\title{
Glutamatergic Neurons in the Piriform Cortex Influence the Activity of D1- and D2-Type Receptor-Expressing Olfactory Tubercle Neurons
}

\author{
Kate A. White, ${ }^{1,2 *}$ Yun-Feng Zhang, ${ }^{3 *}$ Zhijian Zhang, ${ }^{4 *}$ Janardhan P. Bhattarai, ${ }^{3}$ Andrew H. Moberly, ${ }^{3}$ \\ Estelle E. in 't Zandt, ${ }^{1}$ José I. Pena-Bravo, ${ }^{1}$ Huijie Mi, ${ }^{5}$ Xianglian Jia, ${ }^{6}$ Marc V. Fuccillo, ${ }^{3}$ Fuqiang Xu,${ }^{4,6}$ Minghong Ma, ${ }^{3}$ \\ and $\odot$ Daniel W. Wesson ${ }^{1,2}$ \\ ${ }^{1}$ Department of Pharmacology and Therapeutics, University of Florida, Gainesville, Florida 32610, ${ }^{2}$ Department of Neurosciences, Case Western Reserve \\ University, Cleveland, Ohio 44106, ${ }^{3}$ Department of Neuroscience, University of Pennsylvania Perelman School of Medicine, Philadelphia, Pennsylvania \\ 19104, ${ }^{4}$ Key Laboratory of Magnetic Resonance in Biological Systems, Wuhan Institute of Physics and Mathematics, Wuhan 430071, P.R. China, ${ }^{5}$ College of \\ Life Sciences, Wuhan University, Wuhan 430072, China, and ${ }^{6}$ Brain Cognition and Brain Disease Institute (BCBDI), Shenzhen Institutes of Advanced \\ Technology, Chinese Academy of Sciences, Shenzhen 518055, China
}

Sensory cortices process stimuli in manners essential for perception. Very little is known regarding interactions between olfactory cortices. The piriform "primary" olfactory cortex, especially its anterior division (aPCX), extends dense association fibers into the ventral striatum's olfactory tubercle (OT), yet whether this corticostriatal pathway is capable of shaping OT activity, including odor-evoked activity, is unknown. Further unresolved is the synaptic circuitry and the spatial localization of OT-innervating PCX neurons. Here we build upon standing literature to provide some answers to these questions through studies in mice of both sexes. First, we recorded the activity of OT neurons in awake mice while optically stimulating principal neurons in the aPCX and/or their association fibers in the OT while the mice were delivered odors. This uncovered evidence that PCX input indeed influences OT unit activity. We then used patchclamp recordings and viral tracing to determine the connectivity of aPCX neurons upon OT neurons expressing dopamine receptor types D1 or D2, two prominent cell populations in the OT. These investigations uncovered that both populations of neurons receive monosynaptic inputs from aPCX glutamatergic neurons. Interestingly, this input originates largely from the ventrocaudal aPCX. These results shed light on some of the basic physiological properties of this pathway and the cell-types involved and provide a foundation for future studies to identify, among other things, whether this pathway has implications for perception.

Key words: connectivity; olfaction; olfactory cortex; ventral striatum

\section{Significance Statement}

Sensory cortices interact to process stimuli in manners considered essential for perception. Very little is known regarding interactions between olfactory cortices. The present study sheds light on some of the basic physiological properties of a particular intercortical pathway in the olfactory system and provides a foundation for future studies to identify, among other things, whether this pathway has implications for perception.

\section{Introduction}

How does the brain distribute sensory information to enable the successful encoding of stimuli? In nearly all mammalian sensory

Received June 18, 2019; revised Oct. 8, 2019; accepted Oct. 11, 2019.

Author contributions: K.A.W., Y.-F.Z., Z.Z., J.I.P.B., F.X., M.M., and D.W.W. designed research; K.A.W., Y.-F.Z., Z.Z., J.P.B., A.H.M., E.E.i.t.Z., J.I.P.-B., H.M., X.J., and D.W.W. performed research; K.A.W., Y.-F.Z., Z.Z., J.P.B., A.H.M., E.E.i.t.Z., and M.M. analyzed data; K.A.W. and D.W.W. wrote the first draft of the paper; Y.-F.Z., Z.Z., J.P.B., M.M., and D.W.W. wrote the paper; J.I.P.-B., F.X., M.M., and D.W.W. edited the paper; H.M., X.J., and M.V.F. contributed unpublished reagents/analytic tools.

This work was supported by the National Institutes of Health, National Institute on Deafness and Other Communication Disorders, National Institute on Drug Abuse (Grants R01DC014443 and R01DC016519 to D.W.W., Grant R01DC006213 to M.M., Grant R01DA049545 to D.W.W. and M.M., and Grant F31DC016202 to K.A.W.) and the systems, information from the environment is transduced by peripheral sensory receptors and relayed into the thalamus, where

National Natural Science Foundation of China (Grant 31771156 to F.X., Grant 31800885 to Z.Z.). We thank Marie Gadziola for help with in vivo data handling; Chris Ford for advice on medium spiny neuron recordings; Zhonghua Lu and Liping Wang from the Shenzhen Inst of Advanced Technology for providing the VGlut1 probe and platforms for ISH; Yanqiu Li from the Wuhan Institute of Physics and Mathematics (WIPM) for assistance with genotyping mice; and Lingling Xu from WIPM for managing the microscopy platform.

The authors declare no competing financial interests.

*K.A.W., Y.-F.Z., and Z.Z. contributed equally to this work.

Correspondence should be addressed to Daniel W. Wesson at danielwesson@ufl.edu.

https://doi.org/10.1523/JNEUROSCI.1444-19.2019

Copyright $\odot 2019$ the authors 
this input is processed and then distributed into cortical structures that encode stimulus attributes (Sherman, 2012). However, this scheme is not used in the olfactory system wherein odor information bypasses the thalamus and directly enters cortical structures, suggesting that it is the interaction of olfactory cortical structures that is integral for perception (Haberly, 2001). Olfactory sensory neurons extend their axons into olfactory bulb glomeruli (Shepherd et al., 2004; Wilson and Mainen, 2006). From here, mitral and tufted cells relay odor information into secondary olfactory structures, including the piriform cortex (PCX), which holds both posterior and anterior divisions (pPCX and aPCX), olfactory tubercle (OT), anterior olfactory nucleus, and cortical amygdala, among others (Haberly, 2001; Imai, 2014). In addition to extensive bulbar connections, these cortical structures are also heavily interconnected (for review, see Haberly, 2001; Neville and Haberly, 2004; Giessel and Datta, 2014). Thus, there is dispersed connectivity throughout the olfactory system that allows for the potential to transform odor information in likely important manners.

The PCX is often referred to as the "primary" olfactory cortex, and extends massive numbers of glutamatergic association fibers throughout the brain that innervate other olfactory structures (Schwob and Price, 1984a; Shipley and Ennis, 1996; Haberly, 2001; Neville and Haberly, 2004). PCX neural ensembles precisely encode certain odor features (Wilson, 2000a,b; Rennaker et al., 2007; Poo and Isaacson, 2009; Stettler and Axel, 2009; Bolding and Franks, 2017), suggesting that the association fiber network serves to relay odor information among brain structures. Local association fibers within the PCX shape the encoding of odors by plastic actions and recurrent circuitry (Hasselmo et al., 1990; Barkai et al., 1994; Suzuki and Bekkers, 2006, 2011; Linster et al., 2009; Franks et al., 2011; Large et al., 2016).

Do PCX association fibers influence the representation of odors in interconnected olfactory structures? Here we tested this question by interrogating the influence of aPCX association fiber input on the OT. The OT receives direct input from the olfactory bulb (Haberly and Price, 1977; Scott et al., 1980; Zhang et al., 2017) and, like the aPCX, encodes odor identity and intensity (Payton et al., 2012; Xia et al., 2015). However, the OT is the only olfactory structure that is also a component of the ventral striatum (Heimer et al., 1982) that allows it access and perhaps integral capacity for sensory-directed motivated behaviors (Ikemoto, 2007; Wesson and Wilson, 2011; Gadziola and Wesson, 2016; Carlson et al., 2018). As is the case with other striatal structures, the principal class of neurons in the OT are medium spiny neurons (MSNs) (Meredith, 1999). The majority of MSNs express either D1- or D2-type dopamine receptors, with these neurons projecting to areas important for motivated behavior and action selection, including the ventral pallidum and ventral tegmental area (Gerfen et al., 1990; Zhang et al., 2017) (for review (Tian et al., 2010; Smith et al., 2013)). The OT is situated to send odor information into downstream midbrain and striatal structures (Heimer and Wilson, 1975; Wesson and Wilson, 2011; Zhang et al., 2017), making the investigation of aPCX modulation of the OT important.

We know that aPCX association fibers innervate all layers of the OT (Luskin and Price, 1983; Schwob and Price, 1984a,b; Johnson et al., 2000), and electrical stimulation of the aPCX ex vivo in the isolated guinea pig brain elicits postsynaptic potentials in the OT (Carriero et al., 2009). These previous reports provide a rigorous foundation, and herein we investigate: (1) whether PCX input impacts spontaneous and/or odor-evoked activity of OT units, (2) the neurochemical identity and spatial popu- lation of neurons within the aPCX that innervate the OT, and (3) whether aPCX input to the OT occurs upon D1 and/or D2 neurons.

\section{Materials and Methods}

Animals

For in vivo electrophysiology, 2- to 5-month-old C57BL/6 male mice ( $n=17$ for Experiment $1, n=23$ for Experiment 2; RRID:IMSR_JAX: 000664) were housed on a $12 \mathrm{~h}$ light/dark cycle with food and water available ad libitum except when water was restricted for behavioral training (see Behavior subsection below). Mice were single-housed upon intracranial implantation. For ex vivo experiments we crossed two BAC (Gong et al., 2003) mouse lines to allow for identification of cell types. D1-tdTomato BAC (Shuen et al., 2008), obtained as a generous gift from Dr. Nicole Calakos (Duke University; RRID:IMSR_JAX:016204), and D2-EGFP BAC [Tg(Drd2-EGFP)S118Gsat; RRID:MGI:4830460; obtained from the Mutant Mouse Regional resource Center (MMRRC)] transgenic mice were crossed as described previously (Shuen et al., 2008) to obtain mice with dopamine D1- and D2-receptor-expressing MSNs labeled in red and green fluorescence, respectively $(n=9$, both male and female; 1-2 months old). D1-Cre [MMRRC Tg(Drd1a-cre)EY262Gsat; RRID:MMRRC_017264-UCD] and D2-Cre [MMRRC Tg(Drd2-cre) ER44Gsat; RRID:MMRRC_032108-UCD] mouse lines (Gong et al., 2007), acquired from the MMRRC, were used for rabies-assisted viral tracing. Cre-expressing subjects for experimentation were produced by mating transgenic male mice with C57BL/6 females. All experimental procedures were performed in accordance with the guidelines of the National Institutes of Health and were approved by Institutional Animal Care and Use Committees at all institutions.

\section{Stereotaxic surgery and viral injections}

For in vivo and ex vivo experiments, mice were anesthetized with isoflurane (2-4\% in oxygen; Patterson Veterinary) and mounted in a stereotaxic frame with a water-filled heating pad $\left(38^{\circ} \mathrm{C}\right)$ to maintain the mouse's body temperature. Anesthetic depth was verified throughout. A local anesthetic ( $1 \%$ bupivacaine, $0.05 \mathrm{ml}$, s.c.) injection was administered into the wound margin before exposing the dorsal skull. For viral injections, a craniotomy was made above the aPCX (A/P: $\sim 0 \mathrm{~mm}, \mathrm{M} / \mathrm{L}$ : $+2.8 \mathrm{~mm}, \mathrm{D} / \mathrm{V}:+3.5 \mathrm{~mm}$ ), and either a $33 \mathrm{Ga}$ Hamilton microsyringe or a glass micropipette was lowered into the aPCX. Next, $0.5 \mu$ l of AAV5. CaMKII $\alpha$.hChR2.E123T.T159C.p2A.mCherry.WPRE (cell-filling variant) or AAV5.CaMKII $\alpha$.hChR2(H134R).mCherry (non-cell-filling variant; RRID:Addgene_26975) or control vector AAV5.CaMKII $\alpha$.mCherry. WPRE (all undiluted, University of North Carolina Viral Vector Core, Chapel Hill, NC) was infused by a pump at a rate of $0.05 \mu \mathrm{l} / \mathrm{min}$. The E123T/T159C ChR2 double mutant is more sensitive to blue light than H134R, with larger amplitude evoked responses and more rapid photocurrents (Berndt et al., 2011). We began applying the double mutant throughout the course of ongoing experiments with H134R with the intention of more clearly resolving effects and also to take advantage of the cell-filling nature of the $\mathrm{p} 2 \mathrm{~A}$ variant to aid in postmortem histology. These viruses, which were all AAV5 serotype, displayed qualitatively similar spread in the aPCX and a similar number of mice injected with either ChR2-expressing virus contributed data in both in vivo preparations as outlined below. Specifically, for mice contributing data that were implanted with optical fibers in the aPCX and electrodes in the OT, three were injected with AAV5.CaMKII $\alpha$.hChR2(H134R).mCherry and three

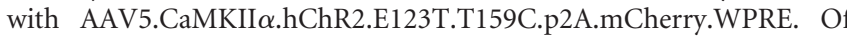
the mice contributing data and implanted with optetrodes into the OT, four were injected with AAV5.CaMKII $\alpha$.hChR2(H134R).mCherry and four were injected with AAV5.CaMKII $\alpha$.hChR2.E123T.T159C.p2A. mCherry.WPRE. The syringe/pipette was withdrawn, the craniotomy sealed with wax, and the wound margin closed. An additional stereotaxic surgery was performed for in vivo experiments to either implant an optical fiber in the aPCX and electrode array in the OT (aPCX stimulation) or an optetrode into the OT (aPCX association fiber stimulation). For fiber and array implants, a craniotomy was made dorsal to the anterior aPCX and a glass optical fiber was lowered into the aPCX. Another craniotomy was made dorsal to the OT and an eight-channel tungsten wire 
electrode was lowered into the OT. For optetrode implants, a craniotomy was made dorsal to the $\mathrm{OT}$ and an optetrode assembly was lowered $\sim 0.3$ $\mathrm{mm}$ dorsal to the OT. Craniotomies were sealed with wax and the implants cemented in place, along with a head bar for head fixation during behavioral experiments (see "Behavior" subsection below). During the recovery period after all surgeries, mice received a daily injection of carprofen (Pfizer Animal Health) or meloxicam (Patterson Veterinary; 5 $\mathrm{mg} / \mathrm{kg}$, s.c. for both) and allowed ad libitum access to food and water.

For viral tracing experiments, viral tools for trans-monosynaptic labeling, which have been described previously (Ren et al., 2018), were packaged by BrainVTA (http://en.brainvta.com/). The helper virus AAV9-EF1a-DIO-histone-BFP-TVA and AAV9-EF1a-DIO-RV-G were titrated at $\sim 3 \times 10^{12}$ genome copies per milliliter, and RV-EnvA- $\Delta \mathrm{G}$ GFP was titrated at $\sim 2 \times 10^{8}$ infecting units per milliliter. The mixture of AAV9-EF1a-DIO-histone-BFP-TVA and AAV9-EF1a-DIO-RV-G (volume ratio: $1: 1,100 \mathrm{nl}$ in total) was injected into the OT $(\mathrm{A} / \mathrm{P}:+1.2$ $\mathrm{mm}, \mathrm{M} / \mathrm{L}:+1.1 \mathrm{~mm}, \mathrm{D} / \mathrm{V}:+4.8 \mathrm{~mm})$ in D1R-Cre $(n=4)$ and D2R-Cre $(n=4)$ male mice, respectively. Two weeks later, $150 \mathrm{nl}$ of RV-EnvA$\Delta \mathrm{G}$-dsRed was injected into the same location of these mice. All injections were restricted to within the OT following established methods (Zhang et al., 2017). One week after the RV injection, the mice were perfused transcardially with PBS (pretreated with $0.1 \%$ diethylpyrocarbonate [DEPC]; Sigma-Aldrich), followed by ice-cold $4 \%$ paraformaldehyde (PFA, 158127 MSDS; Sigma-Aldrich)

\section{Behavior and stimulus presentation}

After surgical recovery, mice for in vivo experiments were water restricted on a $23 \mathrm{~h}$ schedule to no less than $85 \%$ of their body weight to induce motivation to perform a simple task to ensure alertness/engagement throughout recordings. This task, which we call a fixed-interval olfactory task, involved mice being head-fixed in a tube with an odor-port and lick spout directly in front of the mouse's snout and mouth, respectively. Fluid reinforcers (a small drop of $2 \mathrm{~mm}$ saccharin solution) were delivered by a lick spout positioned in front of the animal's mount, with licks detected by an infrared circuit and fluid delivery controlled by a pinch valve. Mice were habituated to head-fixation for $15 \mathrm{~min} /$ session for 2-3 d before stimulus presentation with light isoflurane anesthetization to minimize stress. Mice then began learning the fixed-interval olfactory task, with the following structure for each trial: (1) trial start for $12 \mathrm{~s}$, (2) 1 of 9 pseudorandomly presented stimuli for $2 \mathrm{~s}$, (3) $8 \mathrm{~s}$ poststimulus rest period, and (4) access to fluid reinforcer for $10 \mathrm{~s}$ before new trial start to maintain task motivation. Mice learned to lick for reward to all stimuli presented and worked up to at least 9 trials of each stimulus presentation per session $(\sim 1 \mathrm{~h}$ session/d). Pseudorandomly presented stimuli were one of the nine following: 4 monomolecular odors (isopentyl acetate, heptanal, ethyl butyrate, 1,7 octadiene; Sigma-Aldrich), the same 4 odors $+10 \mathrm{~Hz}$ (20 ms pulse width) aPCX light stimulation, or light stimulation alone. Odors were delivered via an air-dilution olfactometer via independent lines of tubing. All odors were diluted to 1 Torr vapor pressure in mineral oil and delivered via medical-grade nitrogen at a flow rate of 1 $\mathrm{L} / \mathrm{min}$. Mice needed to lick for the fluid reinforcer during the poststimulus period in at least $85 \%$ of trials for the session to be included for analysis of neural activity. In this design, odors were not immediately or explicitly associated with the reinforcer, nor were any odors differentially reinforced. Trials were divided into correct (licked for fluid reinforcer after stimulus) and incorrect (did not lick for reinforcer after stimulus presentation) responses.

\section{Electrophysiology and optical stimulation}

Probe fabrication. Optical fibers, electrode arrays, and optetrodes were custom-made. For optical fibers, glass multimode fiber (300 $\mu \mathrm{m}$ core, 0.39 numerical aperture [NA]; Thorlabs) was cut to the appropriate length and fastened with optical adhesive (Norland) in a $2.5 \mathrm{~mm}$ ceramic ferrule (Thorlabs). For fixed electrode arrays, tungsten wire (A-M Systems) was attached to an Omnetics connector via silver epoxy with a stainless steel wire (A-M Systems), serving as the ground wire, as we have described previously (Gadziola et al., 2015). Tungsten wires were bundled in two polyimide tubes and cut to the appropriate length. Optetrode assembly was performed as described previously (Anikeeva et al., 2011).
Light-intensity output of the final preimplanted fibers was $7-10 \mathrm{~mW}^{3}$ and the distance between tetrode tips and fiber end were 500-800 $\mu \mathrm{m}$ apart to yield a somewhat broad light cone for possible neuron activation.

In vivo electrophysiology and optical stimulation. The connector of the fixed electrode array or optetrode was connected to a head stage and electrode channels were digitized to acquire multiunit activity $(24 \mathrm{kHz}$, $200-3 \mathrm{kHz}$ band-pass filter) and lick events $(300 \mathrm{~Hz})$ for behavioral criterion monitoring. Light stimulation was provided by $447.5 \mathrm{~nm}$ LED (Luxeon Rebel ES; Luxeon Stars) driven by a Thorlabs LED driver connected to a fiber patch cable (ThorLabs; $300 \mu \mathrm{m}$ core multimode fiber) for temporary connection to the implanted ferrule on the animal. Light stimulus intensity, timing, and frequency were determined after conducting pilot experiments where we stimulated the aPCX between 5 and $30 \mathrm{~Hz}$ at $20 \mathrm{~ms}$ pulse width, and intensity was adjusted for every mouse to the lowest intensity possible while still evoking light-induced responses in the OT. We clarify that this open-loop design does not attempt to mimic theta-type respiratory rhythm and is likely driving artificial patterns of activity versus those endogenous to the PCX. This paradigm was selected to provide instead a simple first exploration for whether PCX modulation influences OT unit activity. All data acquisition and stimulus delivery events were controlled simultaneously using a Tucker Davis Technologies digital processor (RRID:SCR_006495). For aPCX association fiber stimulation experiments, tetrodes on the optetrode were advanced $50 \mu \mathrm{m} / \mathrm{session}$ to access new neurons within the OT. For the fixed array, one of eight channels from the multiunit recordings was used as a local reference channel for signal subtraction (Gadziola et al., 2015).

Ex vivo electrophysiology and optical stimulation. For ex vivo whole-cell patch-clamp recordings, mice were deeply anesthetized with ketamine/ xylazine (200 and $20 \mathrm{mg} / \mathrm{kg}$ body weight, respectively) and decapitated. The brains were dissected out and immediately placed in ice-cold cutting solution containing (in $\mathrm{mm}$ ) $92 \mathrm{~N}$-methyl D-glucamine, $2.5 \mathrm{KCl}, 1.2$ $\mathrm{NaH}_{2} \mathrm{PO}_{4}, 30 \mathrm{NaHCO}_{3}, 20$ HEPES, 25 glucose, 5 sodium L-ascorbate, 2 thiourea, 3 sodium pyruvate, $10 \mathrm{MgSO}_{4}$, and $0.5 \mathrm{CaCl}_{2}$; osmolality $\sim 300$ mOsm and $\mathrm{pH} \sim 7.3$, bubbled with $95 \% \mathrm{O}_{2}-5 \% \mathrm{CO}_{2}$. Coronal sections (250 $\mu \mathrm{m}$ thick) containing the aPCX and OT were cut using a Leica VT $1200 S$ vibratome. Brain slices were incubated in oxygenated artificial CSF (ACSF) containing the following (in $\mathrm{mM}$ ): $124 \mathrm{NaCl}, 3 \mathrm{KCl}, 1.3 \mathrm{MgSO}_{4}, 2$ $\mathrm{CaCl}_{2}, 26 \mathrm{NaHCO}_{3}, 1.25 \mathrm{NaH}_{2} \mathrm{PO}_{4}, 5.5$ glucose, and 4.47 sucrose; osmolality $\sim 305 \mathrm{mOsm}$ and $\mathrm{pH} \sim 7.3$, bubbled with $95 \% \mathrm{O}_{2}-5 \% \mathrm{CO}_{2}$ for $\sim 30$ $\mathrm{min}$ at $31^{\circ} \mathrm{C}$ and at least $30 \mathrm{~min}$ at room temperature before use. For recordings, slices were transferred to a recording chamber and continuously perfused with oxygenated ACSF. Fluorescent cells were visualized through a $40 \times$ water-immersion objective on an Olympus BX61WI upright microscope equipped with epifluorescence.

Whole-cell patch-clamp recordings were made under both current and voltage-clamp mode. Recording pipettes were made from borosilicate glass with a Flaming-Brown puller (P-97, Sutter Instruments; tip resistance 5-8 M $\Omega$ ). The pipette solution contained the following (in mM): $120 \mathrm{~K}$-gluconate, $10 \mathrm{NaCl}, 1 \mathrm{CaCl}_{2}, 10 \mathrm{EGTA}, 10 \mathrm{HEPES}, 5 \mathrm{Mg}$ ATP, $0.5 \mathrm{Na}-\mathrm{GTP}$, and 10 phosphocreatine. Electrophysiological recordings were controlled by an EPC-9 amplifier combined with Pulse Software (HEKA) and analyzed using Igor Pro. The signals were filtered at $2.9 \mathrm{kHz}$ and acquired at $50 \mathrm{kHz}$. EPSPs (EPSPs) were further filtered offline at $20 \mathrm{kHz}$ and EPSCs at $0.5 \mathrm{kHz}$. Junction potential $(\sim 9 \mathrm{mV})$ was corrected offline. Light stimulation was delivered through the same objective via pulses of blue laser (473 nm, FTEC2473-V65YF0; Blue Sky Research) with varying lengths. Viral infection in the aPCX was confirmed in brain slices during recordings. No sex differences between male and female mice were evident so data were pooled across mice.

Histology. Histological confirmation of aPCX and OT implant sites for in vivo experiments was performed using DAPI $\left(4^{\prime}, 6\right.$-diamidino-2phenylindole, Invitrogen) stained $40 \mu \mathrm{m}$ coronal brain sections. The number of cells transduced in the aPCX was quantified in 4-6 alternate $20 \mu \mathrm{m}$ sections within a set region of interest in a subset of animals (300 $\mu \mathrm{m} \mathrm{DV} \times 500 \mu \mathrm{m} \mathrm{ML} /$ section; $n=4)$ and compared with the number of anti-NeuN-labeled neurons to provide an estimate of AAV transduction using Nikon NIS Elements and a Nikon Ti2e microscope. The spread of AAV infection was also estimated across all experimental animals using Nikon NIS Elements software $(n=12$ mice, $0.87 \pm 0.04 \mathrm{~mm}$ anterior- 
posterior spread relative to bregma, see Fig. 1). For anti-NeuN immunohistochemistry, free-floating sections were rinsed in tris-buffered saline and diluting buffer, and then blocked in $20 \%$ normal donkey serum for $30 \mathrm{~min}$. Slices were then incubated for $24 \mathrm{~h}$ at $4^{\circ} \mathrm{C}$ with the rabbit antiNeuN primary antibody (ab177487, 1:1000 in diluting buffer, Abcam; RRID:AB_2532109). Sections were rinsed with diluting buffer and then incubated in secondary antibody (donkey anti-rabbit IgG, Alexa Fluor 488, 1:500 in diluting buffer, Abcam) for $2 \mathrm{~h}$ at room temperature before being rinsed with TBS and then $\mathrm{dH}_{2} \mathrm{O}$. Tissue was then mounted on slides with Vectashield mounting medium (VectorLabs) and imaged. To assess association fiber density in the OT, the fluorescent intensity of each layer was calculated as a function of background intensity in ImageJ (Schneider et al., 2012) in 5-6 alternate $40 \mu \mathrm{m}$ sections in a subset of mice $(n=4)$. Data from animals with either unrestricted or unsuccessful labeling were excluded from analysis.

To determine the distribution of RV+ (rabies virus positive) cells in the aPCX for viral tracing experiments, $40 \mu \mathrm{m}$ coronal sections were stored at $-20^{\circ} \mathrm{C}$ floating in $20 \%$ glycerine, $30 \%$ glycol in PBS. A subset of coronal sections across the aPCX (from $\sim 2.34$ to $0.14 \mathrm{~mm}$ bregma, approximately every $240 \mu \mathrm{m}$ ) were washed in PBS and then mounted onto Superfrost Plus slides with $90 \%$ glycerol in PBS and sealed with nail polish. Images of these sections were captured with the Olympus VS120 virtual microscopy slide scanning system (Olympus) using a $10 \times$ objective. aPCX layers, borders, and rostrocaudal axis were delineated based on a standard brain atlas (Paxinos and Franklin, 2000). The dorsal and ventral subregions of the aPCX were divided based on the dorsal edge of the lateral olfactory tract (Ekstrand et al., 2001).

To confirm that OT neurons are innervated by glutamatergic neurons in the aPCX, we performed fluorescent in situ hybridization (FISH) using a VGlut1 probe on the rabies-labeled samples. aPCX coronal sections (15 $\mu \mathrm{m}$ thick) were collected on Superfrost Plus slides and stored at $-80^{\circ} \mathrm{C}$. Sections were blocked with $1 \%$ hydrogen peroxide in PBS at room temperature, rinsed with $\mathrm{PBS}$, and incubated with $1 \mu \mathrm{g} / \mathrm{ml}$ Proteinase $\mathrm{K}$ (Sigma-Aldrich, P-6556) at $37^{\circ} \mathrm{C}$. After a $0.2 \%$ glycine in PBS rinse, sections were then incubated with $0.25 \%$ acetic anhydride in $0.1 \mathrm{M}$ triethanolamine, $\mathrm{pH} 8.0$, and washed again with PBS. VGlut1 probes were prediluted to $0.2 \mathrm{ng} / \mu \mathrm{l}$ with the hybridization buffer (50\% formamide, $300 \mu \mathrm{g} / \mathrm{ml}$ tRNA, $10 \mathrm{~mm}$ Tris $\mathrm{pH} 7.5,10 \%$ dextran sulfate, $1 \times$ Denhalt's solution, $600 \mathrm{~mm} \mathrm{NaCl}, 0.25 \% \mathrm{SDS}$ ), mixed well, preheated at $80^{\circ} \mathrm{C}$, cooled, and applied to each section. After overnight incubation at $56^{\circ} \mathrm{C}$, the sections were washed, first with $2 \times$ SSC, and then $0.2 \times$ SSC twice at $65^{\circ} \mathrm{C}$. Once cooled to room temperature, sections were incubated with peroxidase-conjugated anti-DIG antibody (1:500, Roche) at $37^{\circ} \mathrm{C}$ for $1 \mathrm{~h}$, washed with PBST, and last treated using TSA-plus Cy3 kit (PerkinElmer). Because the GFP signal from RV+ cells was quenched during the ISH process, we further performed the immunohistochemical staining for GFP with rabbit anti-GFP (1:1000, Abcam) and treated the sections with Alexa 488-conjugated goat anti-rabbit secondary (1:1000; Jackson ImmunoResearch) and DAPI and then mounted and sealed as described above. Images were captured as designated above. RV + neurons in different aPCX subregions and VGlut1 colabeled neurons in the aPCX were quantified semiautomatically using FIJI with the cell counter plugin.

\section{Experimental design and statistical analysis}

Behavioral and electrophysiological data analyses were performed using custom scripts in Spike2 (Cambridge Electronic Design; RRID:SCR_000903) and MATLAB (The MathWorks; RRID:SCR_001622). Neurons were sorted offline in Spike2 using template matching and principal component analysis, and spike times exported to MATLAB for analysis. Any putative single unit with $>2 \%$ of events occurring within a $2 \mathrm{~ms}$ interspike interval were excluded from analysis (Gadziola et al., 2015). Significance level for all statistical tests ( $t$ tests, ANOVAs, one-sample $z$ tests, $\chi^{2}$ with Yates' correction) was set at $p<0.05$, and all $t$ tests performed were paired unless otherwise noted. Numbers of animals, brain slices used in recordings/analyses, etc., are reported in their respective sections in this manuscript.

\section{Results}

\section{Viral strategy for the optogenetic stimulation of aPCX principal neurons}

To target aPCX neurons and their association fibers innervating the OT, we injected an AAV viral vector designed to express ChR2 and a reporter fluorophore (mCherry) under control of the calcium/calmodulin-dependent protein kinase ii $\alpha$ (CaMKII $\alpha$ ) promoter, focally, in the aPCX (AAV5.CaMKII $\alpha$.hChR2(E123T/ T159C).p2A.mCherry.WPRE or AAV5.CaMKII $\alpha$.hChR2(H134R). mCherry; Fig. 1A). This approach led to infection of aPCX neurons (Fig. $1 B, C$ ). Anti-NeuN immunohistochemistry was used to label neurons and to aid in quantification of viral infection efficiency. $59.1 \%$ of NeuN-labeled neurons within a set aPCX region of interest were also mCherry+ (interanimal range 51.5-66.2 $\pm 5.6 \%$ SD; Fig. $1 C$, see Materials and Methods). From all colabeled neurons, the greatest numbers were found in layer ii $(78.9 \%$, mean $=101.1$ neurons $)$, followed by layers iii and $\mathrm{i}$, respectively (iii: $16.9 \%$, mean $=21.7$ neurons; $\mathrm{i}$ : $4.2 \%$, mean $=$ 5.5 neurons; $F_{(2,7)}=206.47, p<0.0001$; Fig. $\left.1 D\right)$. Importantly, layer ii contains the densest collection of projection neurons (superficial pyramidal neurons and semilunar cells) extending fibers into the OT (Shipley and Ennis, 1996; Haberly, 2001; Neville and Haberly, 2004; Bekkers and Suzuki, 2013; Mazo et al., 2017).

As expected, we also observed mCherry-expressing aPCX association fibers innervating the OT (Fig. 1E). As anticipated based upon previous tracing studies (Schwob and Price, 1984a,b), these fibers were observed in all cell layers of the OT. To quantify the density of these association fibers, we extracted the fluorescence intensity across OT cell layers from four mice. Fluorescence intensity was greatest in layer ii, followed by layers iii and i $\left(F_{(2,9)}=4.63, p=0.04\right.$; Fig. $\left.1 F\right)$. Thus, this AAV-based approach allows for the targeting of ChR2 into aPCX glutamatergic neurons and their association fibers, including those innervating the OT. We used this same viral approach in two in vivo and one ex vivo optophysiological paradigms as described next.

\section{Activation of aPCX neurons enhances OT activity}

Does the aPCX influence the activity of OT neurons in vivo? We predicted that stimulating aPCX neurons transduced with CaMKII $\alpha$ promoter-dependent ChR2 would result in heightened firing rates among OT units. Three weeks after viral injection as described above, mice were implanted with an optical fiber in the aPCX for light stimulation of ChR2-transduced neurons and an electrode array in the OT to record single-unit neural activity (Fig. 1G,Hi). In the same surgery, mice were implanted with a head bar for subsequent head-fixation. Following several days of recovery, the mice were water deprived and trained to perform a fixed-interval olfactory task (Fig. 2) in which head-fixed mice received one of four odors for $2 \mathrm{~s}$ either with or without simultaneous aPCX stimulation consisting of a blue light stimulus train. Mice also received pseudorandom trials of light alone. Odors were presented during the intertrial interval before a window of reward availability, where mice licked to receive a fluid reinforcer. This design was not intended to capture behavioral effects due to ChR2 stimulation, but simply to ensure the mice were engaged throughout recording sessions by monitoring the occurrence of licking during successive reward windows (Table 1). This fixed-interval reinforcement paradigm, which provides reinforcement between all odors in a manner not closely linked in time with odor delivery, ensures all odors are of similar valence to the mice.

Through both postmortem analyses and behavioral scoring, we focused our analyses on mice that met the following four criteria: (1) AAV expression verified to be restricted within the aPCX, 
A

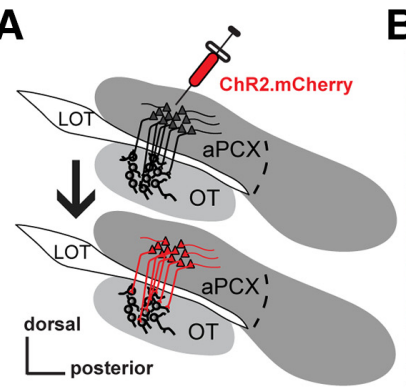

B

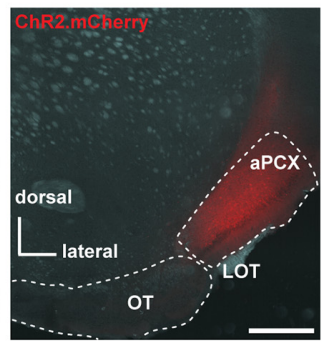

Gi

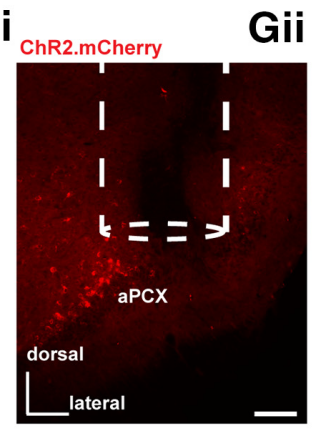

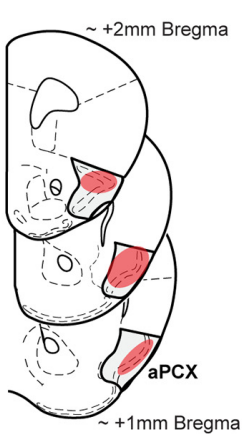

C

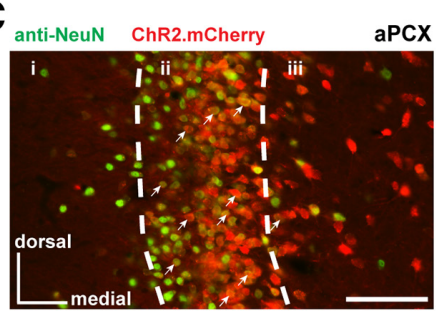

D

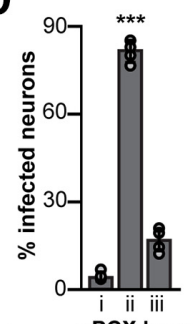

$\mathrm{Hi}$

Hi

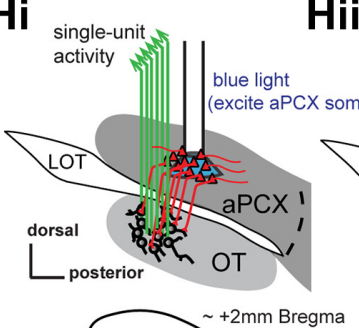

$\mathrm{Hii}$

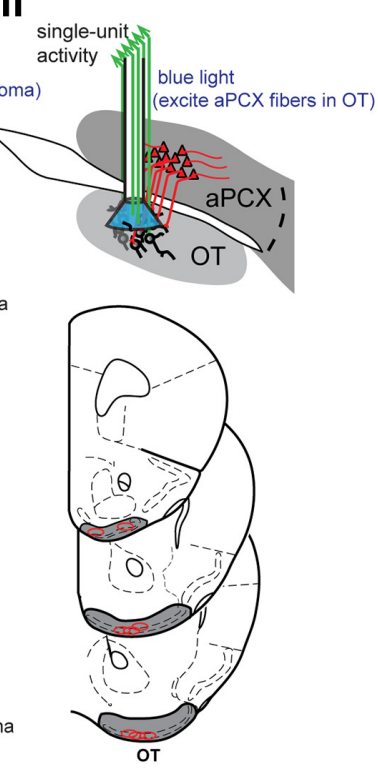

Figure 1. Viral strategy for activating aPCX principal neurons. A, Schematic of the AAV injection procedure that was used to express ChR2 in aPCX neurons and association fibers. L0T, Lateral olfactory tract. After injection of $A A V$ into the aPCX (top) $2-3$ weeks were allowed for viral transduction, after which mice were used for in vivo recordings (bottom). $\boldsymbol{B}$, Representative image of a aPCX AAV injection (AAV5.CaMKIl $\alpha$.hChR2(H134R).mCherry) restricted into specifically the aPCX (white dotted outline). Scale bar, $500 \mu \mathrm{m}$. C, Representative image of aPCXneurons (anti-NeuN, marker for neuronal nuclei) transduced with AAV5.CaMKIl $\alpha$.hChR2.E123T.T159C.p2A.mCherry.WPRE across aPCX layers i-iii. Scale bar, $100 \mu \mathrm{m}$. White arrows indicate colabeled cells. Anti-NeuN histochemistry was performed on tissue from mice not used for recordings. $D$, Quantification of AAV transduction in the aPCX across animals $(n=4)$ as a percentage of $m$ Cherry + cells compared with $\mathrm{NeuN}+$ cells in each aPCX cell layer. ${ }^{* *} p<0.001$. $\boldsymbol{E}$, Image of mCherry + association fibers within the 0 T that originated from the aPCX. Scale bar, $100 \mu \mathrm{m}$. $\boldsymbol{F}$, Average fluorescence intensity (arbitrary units) of aPCXassociation fibers in each 0 T layer across animals $(n=4)$ as a function of background fluorescence. ${ }^{*} p<0.05$. Gi, Representative coronal brain section displaying the location of an optical fiber in aPCX. Scale bar, $100 \mu \mathrm{m}$. Gii, Estimated range of viral vector spread in anterior aPCX across all mice (those used for the preparations shown in both $\boldsymbol{H i}$ and $\boldsymbol{H i i}, n=14$ mice). Qualitative range of viral vector spread across all animals, on average, was $+2.0 \mathrm{~mm}$ bregma to $+1.0 \mathrm{~mm}$ bregma, with the center of infection between +1.5 to $+1.3 \mathrm{~mm}$ bregma. $\boldsymbol{H}$, Location of implant sites for either separate optical fiber into aPCX and fixed electrode array in 0T preparation ( $n=6$ mice; $\boldsymbol{H i}$ ) or optetrode array into the $0 \mathrm{~T}$ preparation ( $n=8$ mice; $\mathrm{Hii})$.

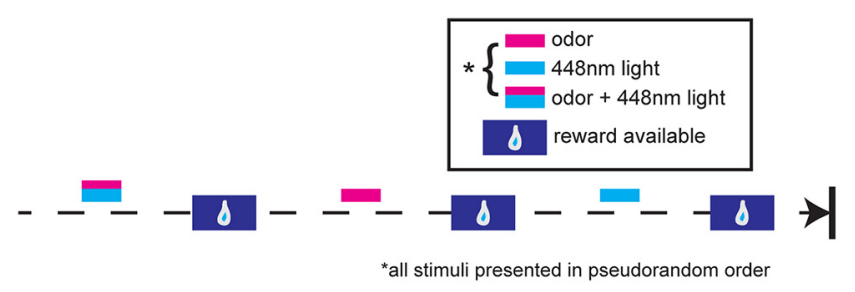

Figure 2. Olfactory fixed-interval task outline. Task structure is shown across three example trials of stimulus presentation. After an intertrial interval, stimulus presentation begins ( $2 \mathrm{~s}$ of either: odor, $10 \mathrm{~Hz}$ blue intracranial light, or odor + light together). Eight seconds after stimulus offset, water-deprived mice were allowed to lick to receive a small fluid reward.

(2) electrode arrays confirmed within the OT, (3) fiber tips localized within the aPCX, and (4) criterion-level behavioral performance (Fig. 1G,Hi, Table 1). Among these mice $(n=8), 6$ had clear multiunit activity from which single units were sorted. The majority of OT neurons display low background firing rates (Gadziola et al., 2015; Xia et al., 2015), providing the possibility that even subtle changes in firing may shape network function. The mean background firing rate of the OT units sampled in this experiment was $2.3 \pm 1.2 \mathrm{~Hz}$ (interunit range: $0.0-5.5 \mathrm{~Hz} ; n=58$ units). We therefore investigated whether, and if so how, aPCX neuron stimulation may influence this low OT neuron firing rate. To do this, for every unit, we compared $2 \mathrm{~s}$ of averaged background activity to $2 \mathrm{~s}$ of averaged light-evoked activity and quantified the magnitude and direction of change upon light stimulation (11-21 trials/unit).

Stimulation of aPCX neurons transduced with the CaMKII $\alpha$ promoter-dependent ChR2 (Fig. 3A) elicited changes in OT unit firing rates (Fig. $3 B-D$ ). Various temporal patterns of responses were observed, including in the form of brief phasic increases in firing, but in some other cases as somewhat sustained increase in firing throughout the light pulses (Fig. 3Bi,Bii). A total of $27.6 \%$ of OT units were significantly modulated by aPCX stimulation (16/58 units; observed in 3 of 6 mice; $p<0.05$, within-units paired $t$ tests comparing background with light evoked; Fig. $3 C$ ). Across these modulated units, light stimulation increased OT 


\begin{tabular}{|c|c|c|}
\hline & Stimulation & \\
\hline & aPCX neuron & aPCX association fiber \\
\hline No. of mice attempted & 17 & 23 \\
\hline No. of mice with successful AAV transduction restricted to the aPCX & 8 & 9 \\
\hline No. of mice with successful fiber/electrode/optetrode implant ${ }^{a}$ & $10(7)$ & $22(8)$ \\
\hline No. of mice shaped to criterion behavior performance ${ }^{a}$ & $13(7)$ & $23(8)$ \\
\hline Average percentage of correct trials across an olfactory task session ${ }^{b}$ & $97.8 \% \pm 1.2 \%(93.0-100.0 \%)$ & $93.7 \% \pm 1.1 \%(85.7-100.0 \%)^{c}$ \\
\hline No. of mice with verified single units & 6 & 8 \\
\hline
\end{tabular}

${ }^{a}$ Numbers in parentheses are the numbers of mice with successful AAV transduction.

${ }^{b}$ Numbers in parentheses are the range of correct responses across sessions.

Values were averaged across sessions throughout which the optetrode was lowered (two to three sessions per mouse).
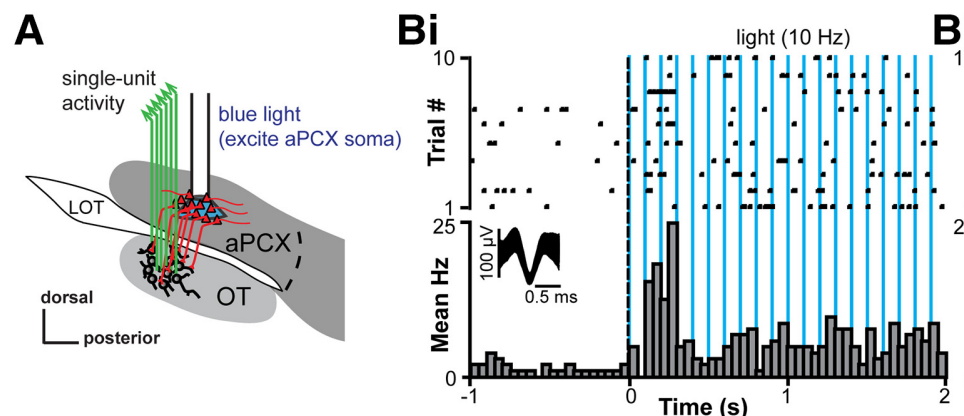

\section{Bii}
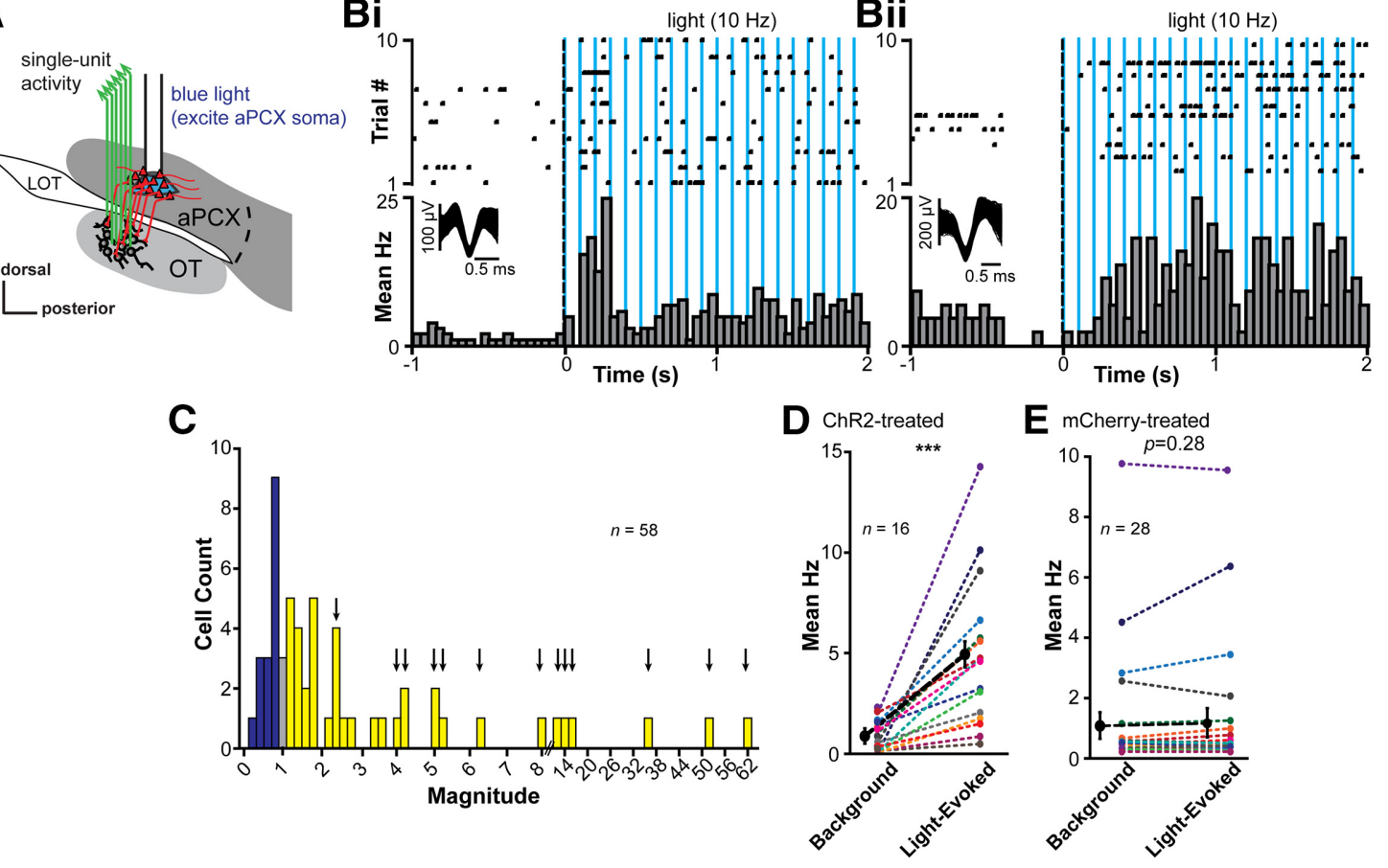

Figure 3. $\mathrm{aPCX}$ neuron activation influences $0 \mathrm{~T}$ neuron firing. $A$, Schematic of the location of the optical fiber in aPCX for light stimulation of aPCX soma and the fixed electrode array in the $0 \mathrm{~T}$ for extracellular recordings. $\boldsymbol{B}$, Examples of significant light-evoked activity of two 0 T single units by stimulation of the aPCX. Each raster plot and histogram represents a single unit's response to light stimulation across 10 trials. Average waveforms for each unit are represented within the histogram. Responses to aPCX light stimulation in these examples evoked either transient (Bi) or sustained (Bii) activity. C, Distribution of the average light-evoked response magnitude (ratio of spike numbers pre, compared with during, stimulation) across the population of recorded units. A majority displayed increases in firing to aPCX light stimulation (yellow), whereas some reduced firing (dark blue) and a small number showed no change (gray). Colors imply direction of changes, not statistical significance. Arrows indicate bars where units contributed to the plot in $\boldsymbol{D}$. Double-line break in $x$-axis denotes change in magnitude binning (from 0.2 to 2 ) to represent sizable changes in magnitude upon light stimulation. Within-unit significance determined by paired $t$ tests comparing firing during background versus light. $\boldsymbol{D}$, Distribution of the change from average background activity to light-evoked activity. Of 16 significantly light-responsive units, all units increased their firing rates. As a population, these units were significantly excited from background activity $\left({ }^{* * *} p<0.001\right)$. Data were normalized to each unit's background firing rate. $\boldsymbol{E}$, Absence of light activation in "control" infected units (aPCX cells without ChR2 expression, AAV5.CaMKIl $\alpha$.mCherry). There is no significant effect of light stimulation on firing rates among individual units ( $p \geq 0.195$; paired $t$ tests) or across all units as a population $(p=0.28)$ in these $\mathrm{mCherry}$-infected animals. Bold black dashed line in $\boldsymbol{D}$ and $\boldsymbol{E}$ indicates the population mean.

unit firing versus baseline $\left(t_{(15)}=-4.79, p=0.00012\right.$; Fig. 3D). Some units showed dramatic increases in firing compared with their low background firing rates (e.g., from $\sim 2 \mathrm{~Hz}$ to near $15 \mathrm{~Hz}$; Fig. 3D). Because all of these six mice had both ChR2 transduction and light fibers in their aPCX, as well as functioning electrodes in their OT, it is not clear why only three of six displayed significantly light-modulated units. However, this outcome holds an internal control: the fact that we observed ChR2-dependent modulation of OT units in only $50 \%$ of the mice highlights that this effect is not due to nonspecific influences of light stimulation on the neurons (artifact) or the animals (e.g., arousal). Further supporting this, light-evoked responses were not observed in two separate mice injected with AAV5.CaMKII $\alpha$.mCherry $(n=28$ units; $p \geq 0.195$, paired $t$ tests; comparing background and light stimulation periods for each unit; Fig. 3E). Thus, activation of glutamatergic aPCX neurons influences OT neural activity.

\section{Activation of aPCX association fibers within the OT} modulates OT activity and influences odor-evoked activity It is possible the above influence on the OT may occur by means of multisynaptic versus direct input from aPCX. Is the aPCX capable of influencing OT activity directly through its association fiber system? To test this, we adapted a new in vivo preparation wherein we used the same viral approach described above along with an optetrode (Anikeeva et al., 2011) to directly stimulate aPCX association fibers specifically within the OT while simultaneously recording OT activity (Fig. 4A). Again, through both postmortem analyses and behavioral scoring, we focused our anal- 
A
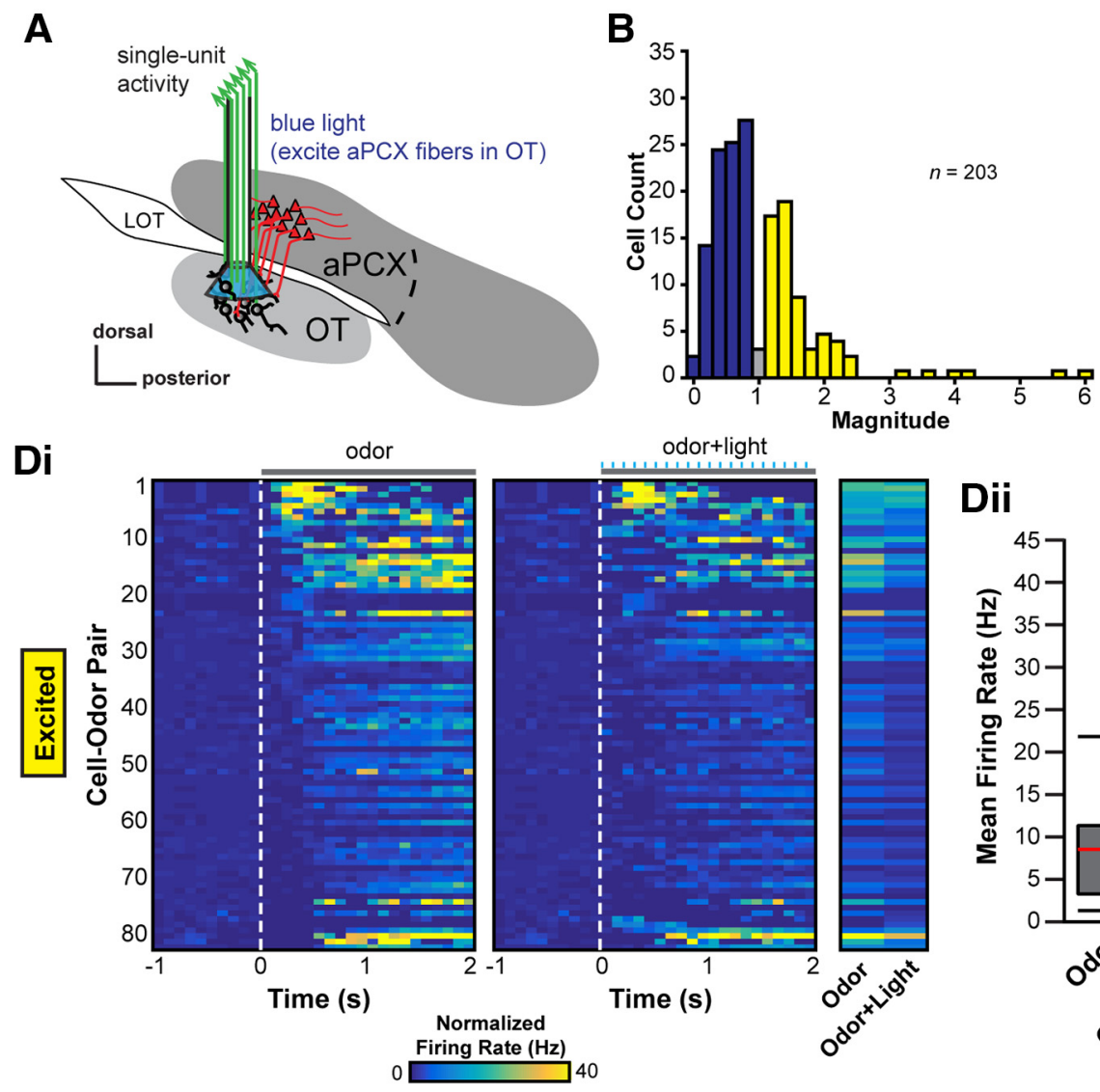

Ei

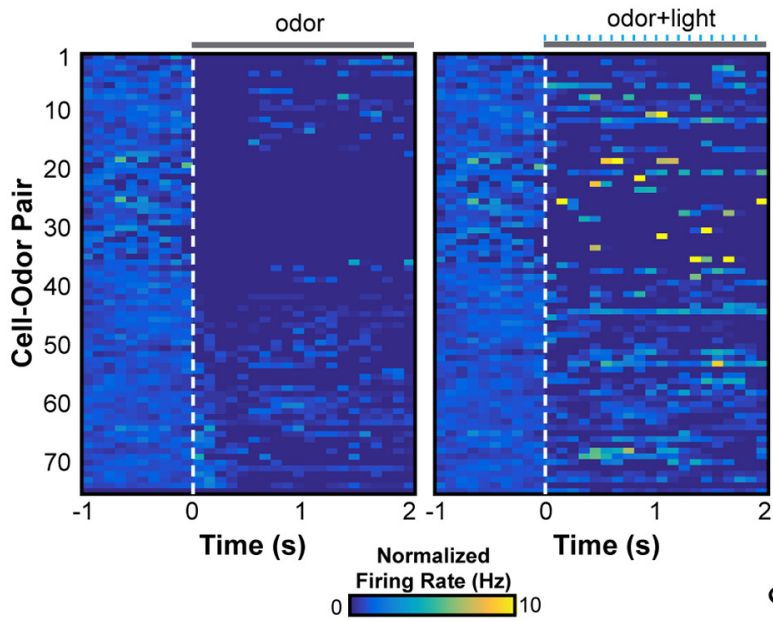

Eii

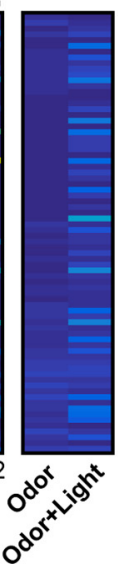

C

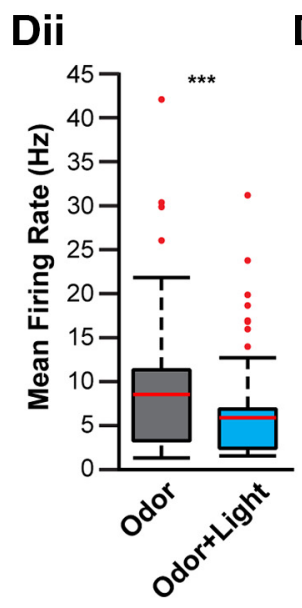

Diii$$
\text { Dii }
$$
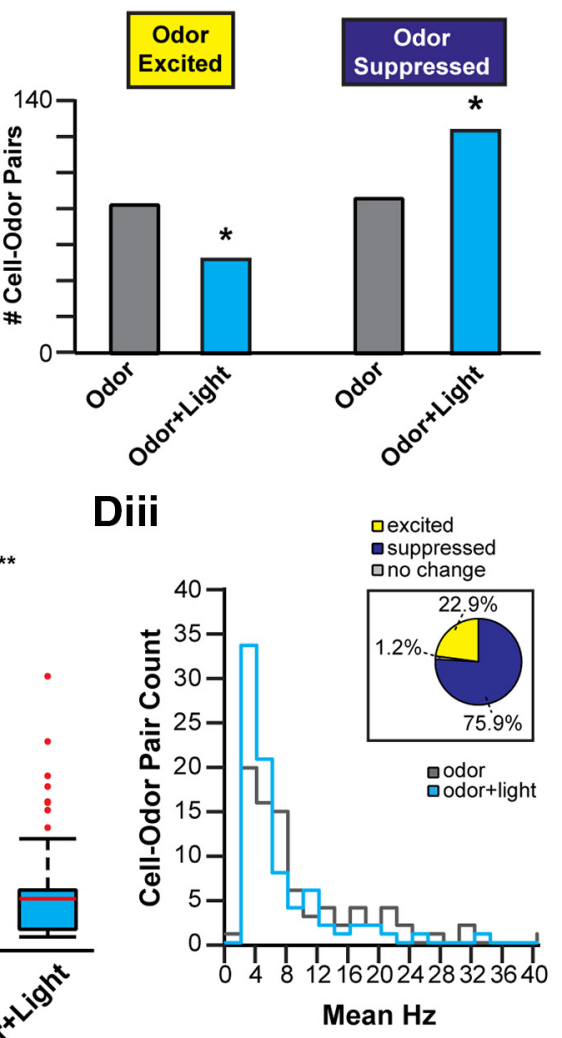

Eiii

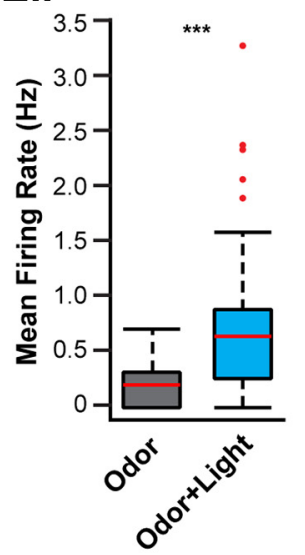

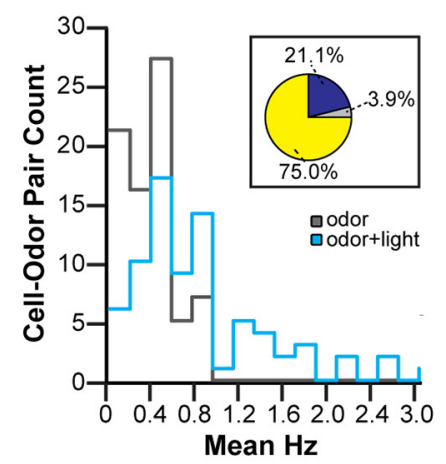

Figure 4. The aPCX influences odor-evoked activity among OT neurons. $A$, Schematic depicting the location of the optetrode assembly in the 0T to record $0 \mathrm{~T}$ extracellular activity and photostimulate aPCX association fiber terminals within the OT. B, Distribution of the average light-evoked response magnitude (ratio of spike numbers before, compared with during, stimulation; no odors presented) across the population of recorded units. Of 203 single units recorded, the majority displayed reduced firing in response to activation of aPCX association fibers (dark blue), while some displayed increases in firing (yellow) and a small number showed no change (gray). Colors imply direction of changes, not statistical significance. C, Population change of odor-responsive $0 T$ neurons during aPCX light stimulation. Data are organized based upon cell- odor pairs which were significantly odor excited or odor suppressed and further organized with or without aPCX light stimulation. ${ }^{*} p<0.05$. D, E, Modulation of cell-odor pair response from odor alone to odor + light stimulation together. $\boldsymbol{D}$, Cell-odor pairs significantly excited by odor. $\boldsymbol{E}$, Cell- odor pairs significantly suppressed by odor. Panels $\boldsymbol{i}$ to iii use the same conventions for both $\boldsymbol{D}$ and $\boldsymbol{E}$. Diand $\boldsymbol{E} \boldsymbol{i}, 2 \mathrm{D}$ histograms representing the change in firing rate from $1 \mathrm{~s}$ of background activity to $2 \mathrm{~s}$ of either odor presentation (left) or odor + light presentation (right). Each row is one unique cell-o odor pair and is the same for both left and right $2 \mathrm{D} \mathrm{histograms.} \mathrm{Each} \mathrm{column} \mathrm{is} \mathrm{a} 100 \mathrm{~ms}$ average firing rate bin for that cell-odor pair. End 2D histogram shows the average evoked response (either odor or odor + light) for each cell- odor pair. Dii and Eii, Boxplot displaying the change in average firing rate across the population for odor alone (gray box) versus odor + light together (blue box). Both plots are significant using a paired $t$ test comparing odor versus odor + light. ${ }^{* * *} p<0.001$. Red line designates the mean, the box designates the $50^{\text {th }}$ percentile range, and the whiskers designate the $25^{\text {th }}$ and $75^{\text {th }}$ percentiles. Red dots are outliers. Diiii and Eiii, Distribution of change from odor alone (gray line) to odor + light together (blue line) from mean firing rate evoked in each case. Pie chart above shows the percentage change from odor alone. Significant changes determined by paired $t$ tests, with those at $p>0.05$ defined as "no change." 
yses on eight mice that met the following three criteria: (1) AAV expression verified to be restricted within the aPCX, (2) optetrode arrays confirmed within the OT, and (3) criterion-level behavioral performance (Table 1). Among these mice, we extracted 203 single units. Corroborating the previous preparation wherein we stimulated aPCX soma directly (Fig. 3), the spontaneous firing rates of these OT units were also low, at $2.1 \pm 3.2 \mathrm{~Hz}$ (interunit range: $0-26.6 \mathrm{~Hz}$ ). We observed light-stimulation of aPCX association fibers shaped OT unit activity. Overall, the population-level impact of this modulation was less than that we observed upon local aPCX activation (i.e., Fig. $3 C, D ; \chi_{(1)}^{2}=$ 13.97, $p=0.002$, comparing modulated units in both experiments). Nevertheless, light-evoked responses were observed in 5 of the 8 mice tested $[5.1 \%$ of all units $(8 / 156)$ were significantly modulated ( $p<0.05$, paired $t$ test; Fig. $4 B]$.

In the fixed internal olfactory task, mice were presented with pseudorandom trials of four different odors, trials of light alone, or trials of light simultaneously with one of the four odors (odor + light) (Fig. 2). We quantified the number of neurons responsive to each of the odors presented with or without activation of aPCX association fibers via the optetrode. Based upon our previous results (Fig. 3), we predicted that activation of aPCX association fibers in the OT would further increase firing rates among OT units during odor presentation and that this would entail greater numbers of odor-excited units. Across the population of 203 single units, $47.8 \%$ were significantly modulated by at least one of the odors presented ( $n=97 ; p<0.05$, within conditions $t$ tests comparing background to odor-evoked activity). From the activity of these 203 single units, we extracted 812 cell-odor pairs to examine the proportion of units responding to odor compared with simultaneous odor and light. As expected, some cell-odor pairs responded to odors in the form of odor-evoked suppression, whereas others responded by increasing their firing rates (Fig. 4C). Upon association fiber activation, the number of cellodor pairs significantly excited by odor decreased from 82 to 52 $\left(\chi_{(1)}^{2}=5.77, p=0.016\right)$, whereas the number of cell-odor pairs significantly suppressed by odor increased from 85 to $123\left(\chi_{(1)}^{2}=\right.$ $5.80, p=0.016$ ). This in some instances was due to light modulation of units not previously modulated by odor in the absence of light. Thus, activating aPCX association fibers within the OT impacts the population of OT units responding to odors.

Next, we quantified the differences in odor responses across individual OT cell-odor pairs. Of the 812 cell-odor pairs, $19.6 \%$ $(n=159)$ were significantly responsive to at least one of the four odors presented when compared with each cell-odor pair's average background firing rate $(p<0.05$, within cell-odor pair $t$ tests). 52.2\% ( $n=83$; Fig. $4 D i-D i i i)$ of these modulated cellodor pairs were excited by odor presentation, whereas $47.8 \%$ displayed odor-evoked suppression of firing ( $n=76$; Fig. $4 E i-$ Eiii). To determine the direction of change within each population, we compared each cell-odor pair's odor-evoked response to that elicited by simultaneous odor and light. Dependent upon whether the cell-odor pair was odor excited or odor suppressed, OT units displayed differing responses to simultaneous aPCX fiber activation. Those units excited by odors were, as a population, less excited by the same odors in the context of aPCX fiber activation $\left(t_{(82)}=5.13, p<0.0001\right.$, Fig. 4 Dii). This was most prominent in cell-odor pairs that represented odors (in absence of light) with low firing rates (Fig. 4Diii). Conversely, odorsuppressed units displayed less suppression during association fiber activation $\left(t_{(75)}=-5.74, p<0.0001\right.$, Fig. 4Eii). The distribution of firing rates for cell-odor pairs encoding odor significantly shifted, suggesting that cell-odor pairs with lower odor-evoked firing rates were most greatly modulated by the occurrence of odor and light together $(D=0.50, p=0.023$, Komolgorov-Smirnoff test; Fig. 4Eiii).

\section{aPCX principal neurons synapse with, and evoke monosynaptic responses within, OT D1- and D2-type MSNs}

The predominant cell type in the OT are MSNs, which can be divided into those expressing either the D1 or D2 receptor. Given the uniquely important signaling pathways and downstream connectivity of these different neuron types (Tian et al., 2010; Smith et al., 2013), we next addressed whether aPCX synaptic input is preferentially directed toward D1 or D2 MSNs. To answer this question, we used an ex vivo paradigm in combination with the same viral approach we used in vivo; however, the injections were performed in D1-tdTomato/D2-EGFP double-transgenic mice to allow for genetically guided identification of D1 or D2 neurons, respectively. Three to 6 weeks after AAV injection, brain slices were acutely prepared and whole-cell patch-clamp recordings performed on OT D1 and D2 MSNs (Fig. 5A). Consistent with previous electrophysiological characterizations of striatal MSNs (Cepeda et al., 2008), OT MSNs had low input resistances (D1 vs D2: $161.7 \pm 7.6$ vs $159.1 \pm 9.3 \mathrm{M} \Omega, n=20$ cells in each group; $\left.t_{(38)}=0.21, p=0.83\right)$. D1 MSNs were less excitable compared with D2 MSNs as evidenced by their display (at least in other striatal structures) of higher firing thresholds and lower firing frequencies upon current injection (Kreitzer and Malenka, 2007) (Fig. 5 B, C). This confirms the ability to segregate these two OT neuron populations during ex vivo recordings.

As expected, ChR2-expressing principal neurons in the aPCX showed instant $(<1 \mathrm{~ms}$ latency) and largely repeatable responses to blue light stimulation (Fig. 6A,B). None of the 106 neurons recorded from the OT (55 D1 and 51 D2 MSNs) showed instant light-evoked responses, indicating that they were not directly infected by the virus. Under current-clamp mode, light pulses evoked EPSPs in some D1 MSNs in the OT (Fig. 6C,D). The evoked responses increased with the pulse duration and typically were able to follow $10 \mathrm{~Hz}$ stimulations. To differentiate OT neurons that receive mono- or polysynaptic connections, we recorded light-evoked EPSCs under voltage-clamp mode and measured the response latency during repeated stimulations (Fig. $6 E$ ). The membrane potential of MSNs was held at $-70 \mathrm{mV}$ near the reversal potential of $\mathrm{GABA}_{\mathrm{A}}$-mediated $\mathrm{Cl}^{-}$currents to eliminate potential contamination from IPSCs. An OT neuron was considered to receive monosynaptic inputs from the aPCX if the response latency was $<6 \mathrm{~ms}$ with the latency jitter $<1 \mathrm{~ms}$. Among these, $24 \%$ of D1 and $16 \%$ of D2 neurons displayed EPSCs upon aPCX fiber activation within the OT with $11 \%$ of D1 and $14 \%$ of D2 neurons receiving monosynaptic excitation (Fig. $6 F$ ). The proportions of D1 and D2 neurons displaying monosynaptic excitation were similar $\left(\chi_{(1)}^{2}=0.009, p=0.923\right)$, reflecting that aPCX inputs to the OT are not biased toward one cell population. Thus, aPCX association fiber activation evokes responses, in some cases monosynaptically, in both D1 and D2 OT MSNs.

\section{Neurons from the ventrocaudal aPCX innervate OT D1- and D2- type MSNs}

Different areas within the aPCX may perform unique functions and possess diverse molecular and circuit features (Haberly, 1973; Price, 1973; Haberly and Price, 1978; Ekstrand et al., 2001; Illig and Haberly, 2003; Luna and Pettit, 2010; Diodato et al., 2016; Large et al., 2018). This led us to ask where projections onto OT D1 and D2 MSNs originate from within the aPCX. Do OT neurons receive input from a spatially distributed population of 
aPCX neurons? Or, are the aPCX neurons innervating the OT spatially organized? OT neurons receive substantial input from neurons in the ipsilateral aPCX (Schwob and Price, 1984a,b), though it is worth mentioning that there is a small population of OT neurons that receive input from the contralateral aPCX (Zhang et al., 2017). Based on this, here we specifically investigated connectivity between the ipsilateral OT and aPCX. We injected a helper viral vector mixture (AAV9EF1a-DIO-histone-BFP-TVA and AAV9EF1a-DIO-RV-G) into the OT of D1-Cre and D2-Cre mice. Two weeks postinfection, a rabies virus (RV-EnvA- $\Delta$ G-GFP; Wickersham et al., 2007) was injected in the same location. Tissue was then collected 1 week following for postmortem analyses. Using this model, in the ipsilateral aPCX we subsequently determined the number of rabies virus-labeled $(\mathrm{RV}+)$ neurons across: (1) aPCX layers, (2) the dorsoventral axis, and (3) the rostrocaudal axis. First though, we sought to confirm the glutamatergic identity of the cells innervating the OT by means of VGlut1 fluorescent in situ hybridization on a subset of D1- and D2-Cre mouse tissue after $\mathrm{RV}$ infection to confirm that indeed the aPCX neurons synapsing upon OT MSNs are glutamatergic (Fig. 7).

The RV approach successfully infected neurons in the aPCX after injection into either D1- or D2-Cre mice, showing that aPCX neurons send monosynaptic input to both of these cell populations (Fig. $8 A, B)$, as also supported by our cell-typespecific patch-clamp recordings (Fig. 6). We first quantified the difference in innervation patterns of both cell types across aPCX layers. Consistent with our previous quantification (Fig. 1D), the majority of neurons innervating both D1 or D2 neurons in the OT originate from aPCX layer ii (D1: $F_{(2,9)}=126.0, p<0.0001$; D2: $F_{(2,9)}=447.9, p<0.0001$ comparing across layers; Fig. $8 C$ ). Next, to determine whether different aPCX subregions uniquely synapse upon these MSN populations, we quantified the number of RV+ cells in each subregion of aPCX across D1-Cre and D2Cre mice. This revealed that more neurons in the ventral versus dorsal aPCX synapsed upon these neurons (D1: $t_{(3)}=8.19, p=$ 0.004 ; D2: $t_{(3)}=8.10, p=0.004$; Fig. $8 D$ ). Examining the rostrocaudal distribution of aPCX innervation of OT, we found that more neurons from the caudal versus rostral aPCX synapsed upon both D1 and D2 neurons (D1: $t_{(6)}=-12.57, p<0.0001$; D2: $t_{(6)}=-1.94, p=0.01$; Fig. $\left.8 E\right)$. Thus, aPCX input to the OT is organized with a ventrocaudal gradient of aPCX neurons innervating both OT D1 and D2 MSNs.

\section{Discussion}

Extensive anatomical work over the last century has examined the vast interconnectivity within the olfactory system (White, 1965; Heimer, 1968; Scott et al., 1980; Luskin and Price, 1983; Haberly, 2001; Neville and Haberly, 2004; Brunjes et al., 2005; Sosulski et al., 2011). Although it is assumed that the way the olfactory sys- tem disseminates odor information across its expansive hierarchical network is critical for olfactory information processing and ultimately odor perception, the function of this interregional connectivity is just beginning to be resolved (Chapuis et al., 2013; Rothermel and Wachowiak, 2014; Sadrian and Wilson, 2015; Howard et al., 2016; Otazu et al., 2015). In the present study, we contribute to this overarching goal by exploring the functionality and the cells involved in one specific and unique pathway: the corticostriatal pathway from the "primary" olfactory cortex into the OT. Although this pathway is anatomically well established (Schwob and Price, 1984a,b; Johnson et al., 2000), the present study yields several specific advances in our knowledge as we outline herein.

\section{Insights into the functional modulation of OT neural activity} by aPCX input

First, whether the aPCX $\rightarrow$ OT pathway may influence OT unit activity and also odor-evoked activity had not been previously investigated. The functional evidence that aPCX association fibers may influence the OT has been derived from electrical stimulations (Carriero et al., 2009), with no investigation yet monitoring OT single units or using odors. As predicted, we showed that aPCX input onto OT neurons modulates the spontaneous activity of OT neurons. aPCX fiber stimulation in the OT also influenced OT unit firing during odor presentation suggesting this pathway may shape the representations of odors in OT. 
A

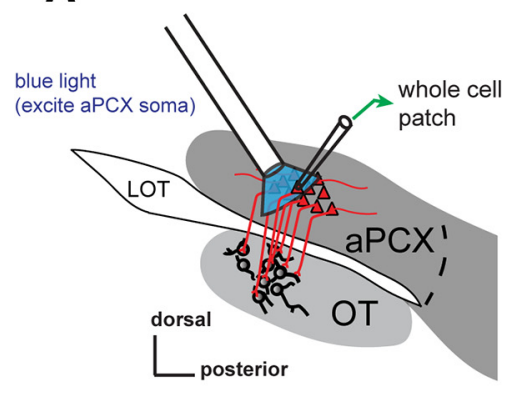

C

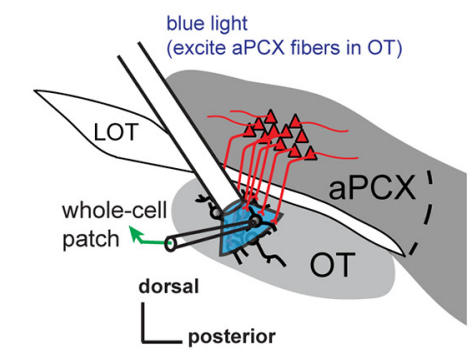

E

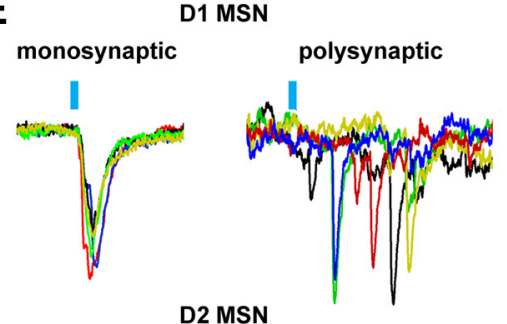

D2 MSN

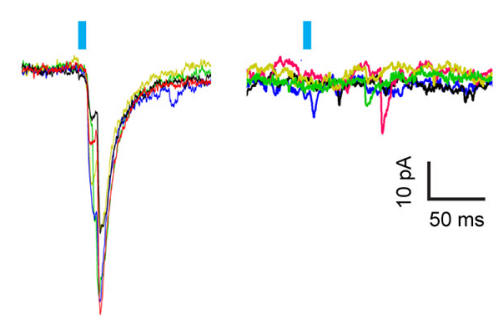

B
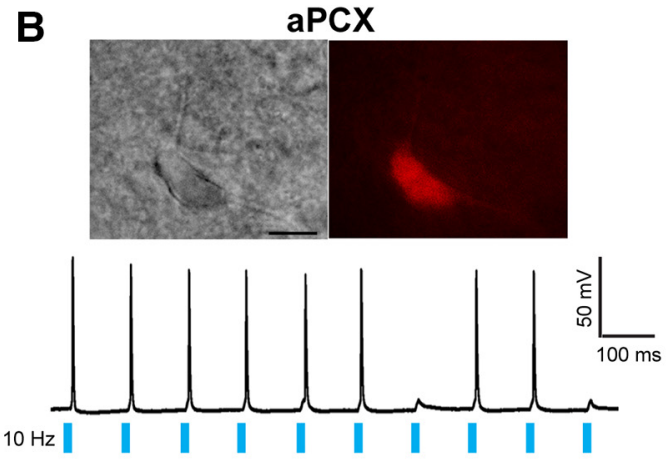

D
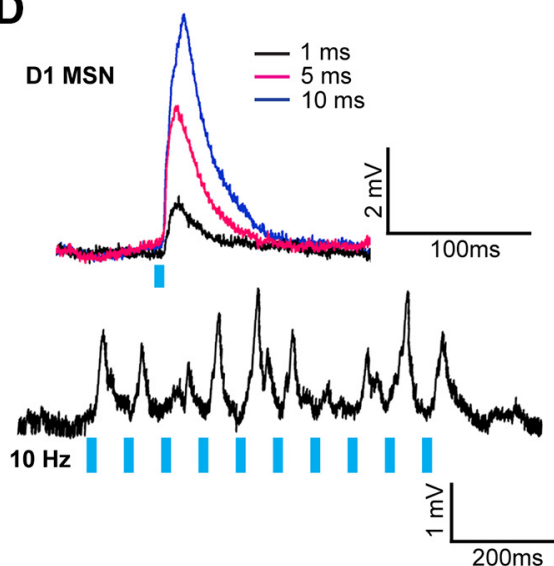

F

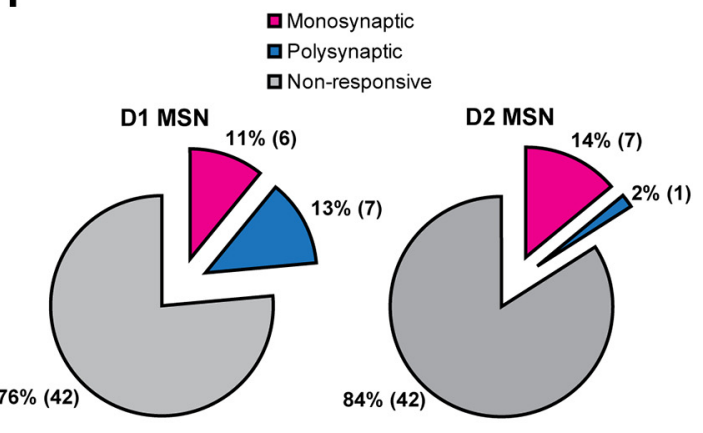

Figure 6. Both $0 T D 1$ and $D 2 M S N$ s receive monosynaptic and polysynaptic input from the aPCX.A, Schematic representing light stimulation of $P C X$ neurons during ex vivo patch-clamp recordings of ChR2 infected aPCX neurons. $\boldsymbol{B}$, An infected pyramidal neuron (red) in the aPCX displayed robust responses to blue light stimulation (1 ms pulses indicated by blue bars). Baseline membrane potential $=-50 \mathrm{mV}$. C, Schematic of the ex vivo whole-cell patch-clamp recording of OT D1 or D2 MSNs and stimulation of aPCX association fibers in the 0T. D, A D1 MSN in the 0T showing light induced EPSPs to different pulse lengths (top) and to a train of $10 \mathrm{~Hz}$ stimuli (bottom) under current-clamp mode. Baseline membrane potential $=-70 \mathrm{mV}$. $\boldsymbol{E}$, Light-evoked monosynaptic or polysynaptic EPSCs in D1 and D2 MSNs under voltage-clamp mode. The holding potential was $-70 \mathrm{mV}$. F, Summary of D1 and D2 cells that displayed light-evoked synaptic responses, organized by whether the evoked response was defined as monosynaptic or polysynaptic (see Materials and Methods). Values in parentheses indicate the number of cells.

Although we hypothesized simply that activation of aPCX association fibers in the OT would further increase firing rates among OT units during odor presentation and that this would entail greater numbers of odor-excited units, instead we found a more complicated outcome. Indeed, the influence of association fiber stimulation was in some cases dependent upon the odor-evoked responsivity of the units. We can only postulate why this would be the case, but it is likely that this change in responsivity is due to convergent effects of aPCX inputs as we show here, and the simultaneous integration of olfactory bulb input (Schneider and Scott, 1983). Based on these results, it appears reasonable to conclude that even though anatomically a great deal of OT input originates from the aPCX (Zhang et al., 2017) (also see Fig. 8), the odor-evoked activity of the OT is influenced by both the olfactory bulb and aPCX. The influence we uncovered onto the OT via the aPCX was in many cases modest, possibly suggestive of a modulatory role. In this reasoning, the olfactory bulb may drive odorevoked activity within the OT, wherein the aPCX provides modulation upon this. As discussed in more detail later on, understanding what content the aPCX relays into the OT versus that which is provided by the olfactory bulb will be informative.

We expect that the amount of OT neuron modulation observed by aPCX activation is likely an underestimation in both our in vivo and ex vivo results. This is especially the case in our paradigms wherein we directly stimulated aPCX fibers within the OT itself. First, this may be due to less than optimal viral infection 

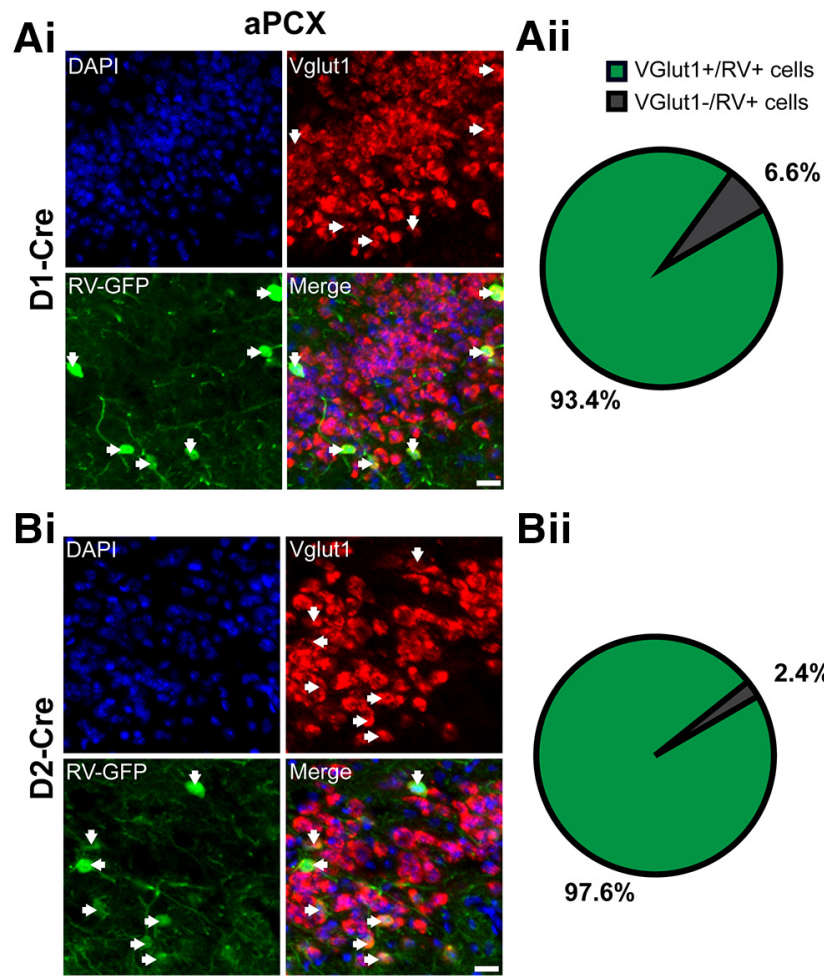

$\mathrm{Bii}$

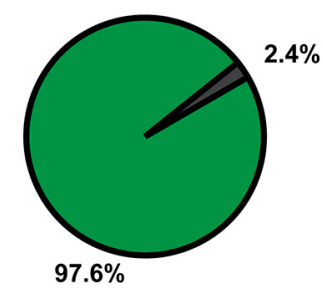

Figure 7. Glutamatergic aPCX neurons directly innervate both $\mathrm{OT} D 1$ and $D 2$ neurons. Neurons shown are from D1-Cre $(\boldsymbol{A})$ and D2-Cre $(\boldsymbol{B})$ mice. $\boldsymbol{A} \boldsymbol{i}$ and $\boldsymbol{B i}$. Representative images showing the colocalization of VGlut1+ neurons (red) and RV + neurons (green) in the aPCX. Arrows designate colabeled neurons. DAPI (blue) was used as a pan-cellular marker for visualization. Scale bar, $20 \mu \mathrm{m}$. Aii and Bii, Pie charts quantifying the percentage of neurons that are both VGlut1+ and RV + (green) or RV + only (gray). The vast majority of RV + cells were also VGlut1 + in both D1-Cre ( $z=11.8, p<0.0001$; one-sample $z$ test for proportions) and D2-Cre (D2: $z=55.6, p<0.0001$; one-sample $z$ test for proportions) mice.

efficiency. Certainly we did not infect all possible glutamatergic neurons in the aPCX. Second, this could be due to the fact that the AAV injections were not targeted specifically to the ventrocaudal portion of the aPCX (which we found in our later tracing studies strongly innervates the OT; Fig. 8). Further, it is likely we severed connections between these structures during slice preparation or surgical implantation of electrodes and optical fibers. Additionally, it is necessary to consider the direct versus indirect effects of the light stimulation paradigms we used. Stimulation of the aPCX by means of CaMKII $\alpha$ promoter controlled ChR2 expression locally excites numerous glutamatergic neurons, which extend projections both within the aPCX and into additional structures via the association fiber network (Shipley and Ennis, 1996; Haberly, 2001; Neville and Haberly, 2004). Thus, changes in OT neuron firing upon local aPCX stimulation could be due to a combination of direct aPCX inputs and polysynaptic inputs from intermediate structures between the aPCX and OT, such as the anterior olfactory nucleus, entorhinal cortex, or amygdala (Haberly, 2001; Neville and Haberly, 2004). Perhaps this is why our direct activation of aPCX fibers within the OT yielded a lower impact upon OT firing rates when compared with local aPCX activation. This would similarly agree with the smaller population-level monosynaptic light-evoked responses in our ex vivo preparation. Interestingly, nevertheless, there were significant light-evoked alterations of neuron firing during odor presentation, suggesting that it may be a synergistic combination of both odor input and aPCX association fiber activation that leads to optimal modulation of OT neuron firing.
Insights into the cell types and spatial organization of the aPCX $\rightarrow$ OT pathway

A second layer of novelty in the present paper is that the cell types involved in the aPCX $\rightarrow$ OT pathway and their organization had not previously been established. Cortical-striatal projections, with differing terminal fields from unique cortices (Heilbronner et al., 2018), are considered to be fundamental for sensory integration. Our viral tracing revealed a spatial organization of aPCX innervation onto OT D1 and D2 neurons, wherein glutamatergic aPCX neurons innervate both cell types in the OT. This is reminiscent of aPCX's topographically organized output upon the orbitofrontal cortex, which also follows along the major axes of the aPCX (Chen et al., 2014). Given the distributed and spatially overlapping representation of odors in the aPCX (Rennaker et al., 2007; Poo and Isaacson, 2009; Stettler and Axel, 2009) and other olfactory cortices (e.g., (Kay et al., 2011)), what are the functional implications of this spatially organized output? The aPCX has historically been subdivided into ventral and dorsal regions, with each having differences in access to, and in their responsivity to, sensory input, as well as differences in their expression of molecular markers, and density of cell layers (Haberly, 1973; Price, 1973; Haberly and Price, 1978; Ekstrand et al., 2001; Illig and Haberly, 2003; Luna and Pettit, 2010; Diodato et al., 2016; Large et al., 2018). Further, there is an established rostrocaudal gradient in the magnitude of inhibition onto aPCX pyramidal neurons, with inhibition being greater in the caudal aPCX (Luna and Pettit, 2010; Large et al., 2018). This effect is largely mediated by layer iii inhibitory neurons, and this inhibitory activity pattern is dependent upon sensory experience (Large et al., 2018). As there is increasing inhibition caudally, and we demonstrated here that more neurons project into the OT from this caudal region, it is possible that these neurons that innervate the OT are subject to differential types of inhibition dependent upon the quality of incoming odor information. Thus, our work adds to other forms of known anatomical and circuit-level heterogeneity within the aPCX and therefore our results inform models for how olfactory information is relayed out of the aPCX. Additional mapping studies among other olfactory structures, and perhaps even into subzones within the spatially vast OT, will be important in defining additional spatial organizations. It is likely that whereas the aPCX itself represents odors in a distributed, spatially overlapping manner (Rennaker et al., 2007; Poo and Isaacson, 2009; Stettler and Axel, 2009), the spatial organization of aPCX efferents as described herein and previously (Chen et al., 2014) allows for the aPCX to exert influences that are unique to both the efferent structure and to odor-evoked activation within aPCX spatial zones.

\section{Limitations}

Some limitations of the present study are important to note. First, this study was not designed to assess a behavioral or perceptual influence of aPCX association fibers. The behavioral paradigm was specifically designed instead to afford analyses of changes in unit activity without behavioral influences. For instance, we did not attempt to provide light stimulation on subsets of trials to investigate behavioral functions of association fiber input. Whether the extent of modulation the aPCX exerts upon the OT entails behavioral or perceptual significance remains to be determined. Second, we interrogated aPCX association fiber input effects in the presence of a functional olfactory bulb. Future studies will be needed to understand what information the PCX relays into the OT versus what is provided by the olfactory bulb. The relative contribution of each of these input pathways is certainly an im- 
A

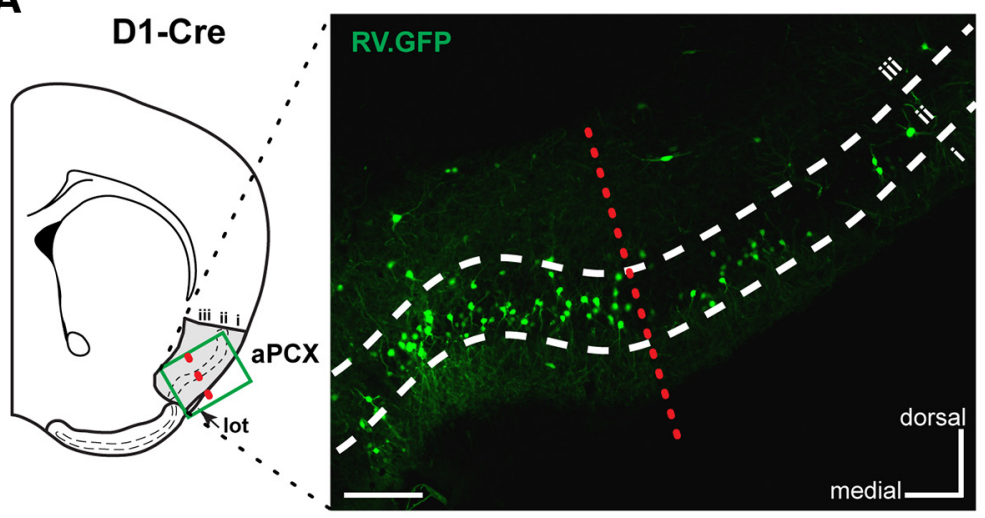

B

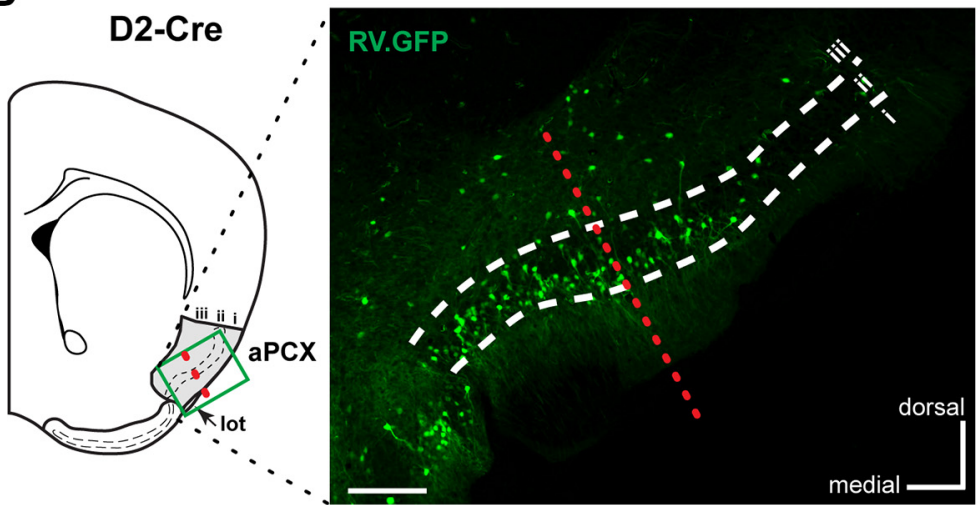

C
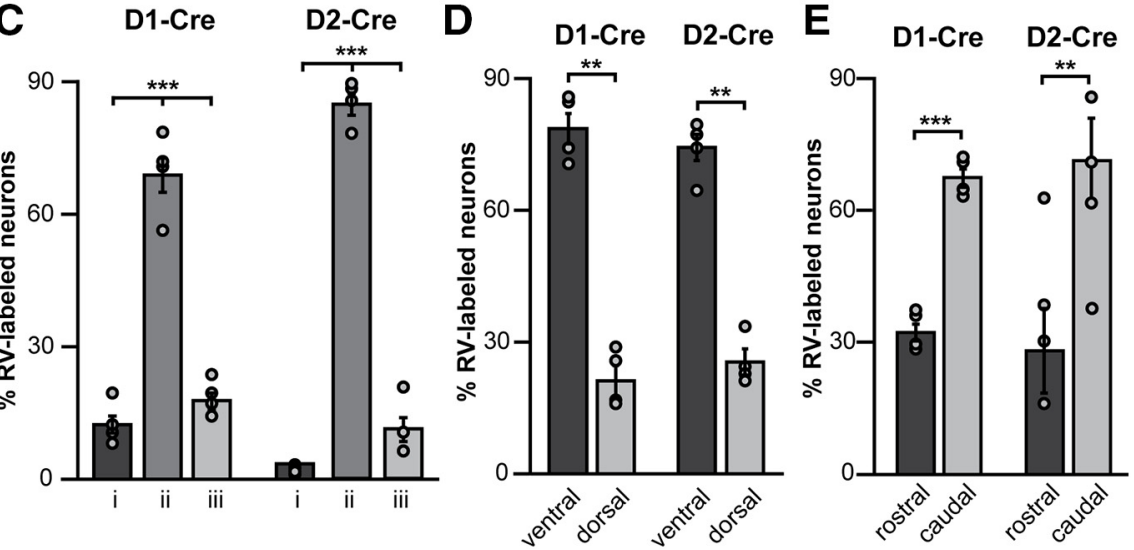

Figure 8. Neurons from the ventrocaudal aPCX innervate OT D1- and D2- type MSNs. $\boldsymbol{A}, \boldsymbol{B}$, Coronal brain section schematic of analyses regions ( $\sim 0 \mathrm{~mm} \mathrm{~A} / \mathrm{P}$ bregma) and representative coronal brain sections displaying aPCX neurons labeled by the rabies virus (RV) (RV-EnvA- $\Delta$ G-GFP, green) from the OT in both D1-Cre $(\boldsymbol{A})$ and D2-Cre mice $(\boldsymbol{B})$. Scale bar, $200 \mu \mathrm{m}$. Green boxes in schematics indicate approximate regions used to collect images for analyses. Red dashed line indicates the approximate boundary of ventral versus dorsal aPCX.C, Percentage of RV + neurons across all aPCX layers. D, Percentage of RV + neurons localized within the ventral and dorsal aPCX subregions. $\boldsymbol{E}$, Percentage of $R V+$ neurons localized within the rostral and caudal aPCX subregions. Individual data points in $\boldsymbol{C}$ to $\boldsymbol{E}$ indicate within animal means. ${ }^{* *} p<0.01,{ }^{* * *} p<0.0001$.

portant issue. Third, the ChR2 stimulation paradigm broadly stimulated PCX neurons and was not engineered to mimic the endogenous activity of the PCX. The optical stimulation design we used was selected based upon pilot experiments to simply uncover an effect, which it did. Additional research using closedloop stimulation/inhibition paradigms to investigate this pathway may likely yield great insight, especially if designed to target more specific portions or cell-types of the aPCX. This would further allow for analyses into the temporal responses of OT neurons upon aPCX stimulation, which may help better under- stand the present results in terms of why some neurons showed reduced, versus increased, evoked responses. Additionally, while OT neurons may encode features of odors, such as their identity, intensity, and more (Wesson and Wilson, 2010; Payton et al., 2012; Xia et al., 2015), due to the need to include light stimulation as a stimulus in $\sim 66 \%$ of trials, we simply were not allowed enough time to screen units in these awake mice for how PCX input may shape these finer features of odor coding. Finally, we know very little about OT neurons and how they interact with each other. This presents a weakness in our ability to interpret and explain the observed effects. For instance, why is it that stimulation of excitatory PCX neurons may suppress odor-evoked responses, as we observed in some cases? Our studies are unable to directly answer this. Striatal MSNs extend collaterals upon one another, which while shown to modulate neighboring cells (Taverna et al., 2008), are not understood in the context of OT in vivo physiology nor in the context of behavior. Beyond this, we presently do not know specific roles for MSN cell types within the OT, nor if the strict definition of the direct or indirect pathways even applies to them (Smith et al., 2013; Ikemoto and Bonci, 2014; Kupchik et al., 2015). That stated, our finding that aPCX input falls upon both D1 and D2 neuron populations raises the exciting and likely possibility that this pathway may shape the display of odordirected motivated behaviors.

\section{Conclusions}

The input upon OT MSN populations by the aPCX highlights one route whereby the aPCX may shape the availability of odor information within an interconnected brain structure. We predict that the OT, serving as the olfactory striatum and receiving input from numerous olfactory centers (Wesson and Wilson, 2011), participates in concert with other olfactory cortices, beyond the aPCX itself, to distribute odor information from the olfactory bulb into critical basal ganglia centers that have direct roles in regulating motor behaviors including stimulus approach and even consummation. This initial investigation into the aPCX $\rightarrow$ OT pathway should serve as a foundation for future research to define functional roles for this pathway in behavior and possibly perception.

\section{References}

Anikeeva P, Andalman AS, Witten I, Warden M, Goshen I, Grosenick L, Gunaydin LA, Frank LM, Deisseroth K (2011) Optetrode: a multichan- 
nel readout for optogenetic control in freely moving mice. Nat Neurosci 15:163-170.

Barkai E, Bergman RE, Horwitz G, Hasselmo ME (1994) Modulation of associative memory function in a biophysical simulation of rat piriform cortex. J Neurophysiol 72:659-677.

Bekkers JM, Suzuki N (2013) Neurons and circuits for odor processing in the piriform cortex. Trends Neurosci 36:429-438.

Berndt A, Schoenenberger P, Mattis J, Tye KM, Deisseroth K, Hegemann P, Oertner TG (2011) High-efficiency channelrhodopsins for fast neuronal stimulation at low light levels. Proc Natl Acad Sci U S A 108:75957600.

Bolding KA, Franks KM (2017) Complementary codes for odor identity and intensity in olfactory cortex. Elife 6:e22630.

Brunjes PC, Illig KR, Meyer EA (2005) A field guide to the anterior olfactory nucleus (cortex). Brain Res Brain Res Rev 50:305-335.

Carlson KS, Gadziola MA, Dauster ES, Wesson DW (2018) Selective attention controls olfactory decisions and the neural encoding of odors. Curr Biol 28:2195-2205.e4.

Carriero G, Uva L, Gnatkovsky V, de Curtis M (2009) Distribution of the olfactory fiber input into the olfactory tubercle of the in vitro isolated guinea pig brain. J Neurophysiol 101:1613-1619.

Cepeda C, André VM, Yamazaki I, Wu N, Kleiman-Weiner M, Levine MS (2008) Differential electrophysiological properties of dopamine D1 and D2 receptor-containing striatal medium-sized spiny neurons. Eur J Neurosci 27:671-682.

Chapuis J, Cohen Y, He X, Zhang Z, Jin S, Xu F, Wilson DA (2013) Lateral entorhinal modulation of piriform cortical activity and fine odor discrimination. J Neurosci 33:13449-13459.

Chen CF, Zou DJ, Altomare CG, Xu L, Greer CA, Firestein SJ (2014) Nonsensory target-dependent organization of piriform cortex. Proc Natl Acad Sci U S A 111:16931-16936.

Diodato A, Ruinart de Brimont M, Yim YS, Derian N, Perrin S, Pouch J, Klatzmann D, Garel S, Choi GB, Fleischmann A (2016) Molecular signatures of neural connectivity in the olfactory cortex. Nat Commun 7:12238.

Ekstrand JJ, Domroese ME, Johnson DM, Feig SL, Knodel SM, Behan M, Haberly LB (2001) A new subdivision of anterior piriform cortex and associated deep nucleus with novel features of interest for olfaction and epilepsy. J Comp Neurol 434:289-307.

Franks KM, Russo MJ, Sosulski DL, Mulligan AA, Siegelbaum SA, Axel R (2011) Recurrent circuitry dynamically shapes the activation of piriform cortex. Neuron 72:49-56.

Gadziola MA, Wesson DW (2016) The neural representation of goaldirected actions and outcomes in the ventral Striatum's olfactory tubercle. J Neurosci 36:548-560.

Gadziola MA, Tylicki KA, Christian DL, Wesson DW (2015) The olfactory tubercle encodes odor valence in behaving mice. J Neurosci 35:45154527.

Gerfen CR, Engber TM, Mahan LC, Susel Z, Chase TN, Monsma FJ Jr, Sibley DR (1990) D1 and D2 dopamine receptor-regulated gene expression of striatonigral and striatopallidal neurons. Science 250:1429-1432.

Giessel AJ, Datta SR (2014) Olfactory maps, circuits and computations. Curr Opin Neurobiol 24:120-132.

Gong S, Zheng C, Doughty ML, Losos K, Didkovsky N, Schambra UB, Nowak NJ, Joyner A, Leblanc G, Hatten ME, Heintz N (2003) A gene expression atlas of the central nervous system based on bacterial artificial chromosomes. Nature 425:917-925.

Gong S, Doughty M, Harbaugh CR, Cummins A, Hatten ME, Heintz N, Gerfen CR (2007) Targeting Cre recombinase to specific neuron populations with bacterial artificial chromosome constructs. J Neurosci 27:98179823.

Haberly LB (1973) Unitary analysis of opossum prepyriform cortex. J Neurophysiol 36:762-774.

Haberly LB (2001) Parallel-distributed processing in olfactory cortex: new insights from morphological and physiological analysis of neuronal circuitry. Chem Senses 26:551-576.

Haberly LB, Price JL (1977) The axonal projection patterns of the mitral and tufted cells of the olfactory bulb in the rat. Brain Res 129:152-157.

Haberly LB, Price JL (1978) Association and commissural fiber systems of the olfactory cortex of the rat. I. Systems originating in the piriform cortex and adjacent areas. J Comp Neurol 178:711-740.

Hasselmo ME, Wilson MA, Anderson BP, Bower JM (1990) Associative memory function in piriform (olfactory) cortex: computational modeling and neuropharmacology. Cold Spring Harb Symp Quant Biol 55:599_ 610 .

Heilbronner SR, Meyer MAA, Choi EY, Haber SN (2018) How do corticostriatal projections impact on downstream pallidal circuitry? Brain Struct Funct 223:2809-2821.

Heimer L (1968) Synaptic distribution of centripedal and centrifugal nerve fibers in the olfactory system in the rat. J Anat 103:413-432.

Heimer L, Wilson RD (1975) The subcortical projections of the allocortex: similarities in the neural associations of the hippocampus, the piriform cortex, and the neocortex, Golgi Centennial Symposium, Proceedings. New York: Raven.

Heimer L, Switzer RD, Van Hoesen GW (1982) Ventral striatum and ventral pallidum: components of the motor system? Trends Neurosci 5:83-87.

Howard JD, Kahnt T, Gottfried JA (2016) Converging prefrontal pathways support associative and perceptual features of conditioned stimuli. Nat Commun 7:11546.

Ikemoto S (2007) Dopamine reward circuitry: two projection systems from the ventral midbrain to the nucleus accumbens-olfactory tubercle complex. Brain Res Rev 56:27-78.

Ikemoto S, Bonci A (2014) Neurocircuitry of drug reward. Neuropharmacology 76:329-341.

Illig KR, Haberly LB (2003) Odor-evoked activity is spatially distributed in piriform cortex. J Comp Neurol 457:361-373.

Imai T (2014) Construction of functional neuronal circuitry in the olfactory bulb. Semin Cell Dev Biol 35:180-188.

Johnson DM, Illig KR, Behan M, Haberly LB (2000) New features of connectivity in piriform cortex visualized by intracellular injection of pyramidal cells suggest that "primary" olfactory cortex functions like "association" cortex in other sensory systems. J Neurosci 20:6974-6982.

Kay RB, Meyer EA, Illig KR, Brunjes PC (2011) Spatial distribution of neural activity in the anterior olfactory nucleus evoked by odor and electrical stimulation. J Comp Neurol 519:277-289.

Kreitzer AC, Malenka RC (2007) Endocannabinoid-mediated rescue of striatal LTD and motor deficits in Parkinson's disease models. Nature 445: 643-647.

Kupchik YM, Brown RM, Heinsbroek JA, Lobo MK, Schwartz DJ, Kalivas PW (2015) Coding the direct/indirect pathways by D1 and D2 receptors is not valid for accumbens projections. Nat Neurosci 18:1230-1232.

Large AM, Vogler NW, Mielo S, Oswald AM (2016) Balanced feedforward inhibition and dominant recurrent inhibition in olfactory cortex. Proc Natl Acad Sci U S A 113:2276-2281.

Large AM, Vogler NW, Canto-Bustos M, Friason FL, Schick P, Oswald AM (2018) Differential inhibition of pyramidal cells and inhibitory interneurons along the rostrocaudal axis of anterior piriform cortex. Proc Natl Acad Sci U S A 115:E8067-E8076.

Linster C, Menon AV, Singh CY, Wilson DA (2009) Odor-specific habituation arises from interaction of afferent synaptic adaptation and intrinsic synaptic potentiation in olfactory cortex. Learn Mem 16:452-459.

Luna VM, Pettit DL (2010) Asymmetric rostro-caudal inhibition in the primary olfactory cortex. Nat Neurosci 13:533-535.

Luskin MB, Price JL (1983) The laminar distribution of intracortical fibers originating in the olfactory cortex of the rat. J Comp Neurol 216:292-302.

Mazo C, Grimaud J, Shima Y, Murthy VN, Lau CG (2017) Distinct projection patterns of different classes of layer 2 principal neurons in the olfactory cortex. Sci Rep 7:8282.

Meredith GE (1999) The synaptic framework for chemical signaling in nucleus accumbens. Ann N Y Acad Sci 877:140-156.

Neville KR, Haberly L (2004) Olfactory cortex. In: The synaptic organization of the brain, Ed 5 (Shepherd GM, ed), pp. 415-454. New York: OUP.

Otazu GH, Chae H, Davis MB, Albeanu DF (2015) Cortical feedback decorrelates olfactory bulb output in awake mice. Neuron 86:1461-1477.

Paxinos G, Franklin K (2000) The mouse brain in stereotaxic coordinates, Ed 2. San Diego: Academic

Payton CA, Wilson DA, Wesson DW (2012) Parallel odor processing by two anatomically distinct olfactory bulb target structures. PLoS One 7:e34926.

Poo C, Isaacson JS (2009) Odor representations in olfactory cortex: sparse coding, global inhibition, and oscillations. Neuron 62:850-861.

Price JL (1973) An autoradiographic study of complementary laminar patterns of termination of afferent fibers to the olfactory cortex. J Comp Neurol 150:87-108. 
Ren M, Tian J, Zhao P, Luo J, Feng Z, Gong H, Li X (2018) Simultaneous acquisition of multicolor information from neural circuits in resinembedded samples. Front Neurosci 12:885.

Rennaker RL, Chen CF, Ruyle AM, Sloan AM, Wilson DA (2007) Spatial and temporal distribution of odorant-evoked activity in the piriform cortex. J Neurosci 27:1534-1542.

Rothermel M, Wachowiak M (2014) Functional imaging of cortical feedback projections to the olfactory bulb. Front Neural Circuits 8:73.

Sadrian B, Wilson DA (2015) Optogenetic stimulation of lateral amygdala input to posterior piriform cortex modulates single-unit and ensemble odor processing. Front Neural Circuits 9:81.

Schneider CA, Rasband WS, Eliceiri KW (2012) NIH image to ImageJ: 25 years of image analysis. Nat Methods 9:671-675.

Schneider SP, Scott JW (1983) Orthodromic response properties of rat olfactory bulb mitral and tufted cells correlate with their projection patterns. J Neurophysiol 50:358-378.

Schwob JE, Price JL (1984a) The development of axonal connections in the central olfactory system of rats. J Comp Neurol 223:177-202.

Schwob JE, Price JL (1984b) The development of lamination of afferent fibers to the olfactory cortex in rats, with additional observations in the adult. J Comp Neurol 223:203-222.

Scott JW, McBride RL, Schneider SP (1980) The organization of projections from the olfactory bulb to the piriform cortex and olfactory tubercle in the rat. J Comp Neurol 194:519-534.

Shepherd GM, Chen WR, Greer CA (2004) Olfactory bulb. In: The synaptic organization of the brain, Ed 5 (Shepherd GM, ed), pp. 165-216. Oxford: OUP.

Sherman SM (2012) Thalamocortical interactions. Curr Opin Neurobiol 22:575-579.

Shipley MT, Ennis M (1996) Functional organization of olfactory system. J Neurobiol 30:123-176.

Shuen JA, Chen M, Gloss B, Calakos N (2008) Drd1a-tdTomato BAC transgenic mice for simultaneous visualization of medium spiny neurons in the direct and indirect pathways of the basal ganglia. J Neurosci 28:2681-2685.

Smith RJ, Lobo MK, Spencer S, Kalivas PW (2013) Cocaine-induced adaptations in D1 and D2 accumbens projection neurons (a dichotomy not necessarily synonymous with direct and indirect pathways). Curr Opin Neurobiol 23:546-552.

Sosulski DL, Bloom ML, Cutforth T, Axel R, Datta SR (2011) Distinct representations of olfactory information in different cortical centres. Nature 472:213-216.

Stettler DD, Axel R (2009) Representations of odor in the piriform cortex. Neuron 63:854-864.

Suzuki N, Bekkers JM (2006) Neural coding by two classes of principal cells in the mouse piriform cortex. J Neurosci 26:11938-11947.

Suzuki N, Bekkers JM (2011) Two layers of synaptic processing by principal neurons in piriform cortex. J Neurosci 31:2156-2166.

Taverna S, Ilijic E, Surmeier DJ (2008) Recurrent collateral connections of striatal medium spiny neurons are disrupted in models of Parkinson's disease. J Neurosci 28:5504-5512.

Tian X, Kai L, Hockberger PE, Wokosin DL, Surmeier DJ (2010) MEF-2 regulates activity-dependent spine loss in striatopallidal medium spiny neurons. Mol Cell Neurosci 44:94-108.

Wesson DW, Wilson DA (2010) Smelling sounds: olfactory-auditory sensory convergence in the olfactory tubercle. J Neurosci 30:3013-3021.

Wesson DW, Wilson DA (2011) Sniffing out the contributions of the olfactory tubercle to the sense of smell: hedonics, sensory integration, and more? Neurosci Biobehav Rev 35:655-668.

White LE (1965) Olfactory bulb projections of the rat. Anat Rec 152:465-479.

Wickersham IR, Lyon DC, Barnard RJ, Mori T, Finke S, Conzelmann KK, Young JAT, Callaway EM (2007) Monosynaptic restriction of transsynaptic tracing from single, genetically targeted neurons. Neuron 53:639-647.

Wilson DA (2000a) Odor specificity of habituation in the rat anterior piriform cortex. J Neurophysiol 83:139-145.

Wilson DA (2000b) Comparison of odor receptive field plasticity in the rat olfactory bulb and anterior piriform cortex. J Neurophysiol 84:3036-3042.

Wilson RI, Mainen ZF (2006) Early events in olfactory processing. Annu Rev Neurosci 29:163-201.

Xia CZ, Adjei S, Wesson DW (2015) Coding of odor stimulus features among secondary olfactory structures. J Neurophysiol 114:736-745.

Zhang Z, Zhang H, Wen P, Zhu X, Wang L, Liu Q, Wang J, He X, Wang H, Xu F (2017) Whole-brain mapping of the inputs and outputs of the medial part of the olfactory tubercle. Front Neural Circuits 11:52. 